zing leukocytes. J. exp. Med. 110, 969 (1959). - [7] ALrman, K. I., and S. N. SwISHER: Incorporation of acetate-2 ${ }^{14} \mathrm{C}$ into human erythrocyte stroma as a function of storage. Nature (Lond.) 174, 459 (1954). - [8] Rowe, C. E.: Phospholipid metabolism in human erythrocytes. Biochem. J. 71, Ip (1959). [9] LYNen, F., T. Hopper-K Essel u. H. EgGERER: Zur Biosynthese der Fettsäuren. III. Die Fettsäuresynthetase der Hefe und die Bildung enzymgebundener Acetessigsäure. Biochem. J. 340, 95 (1964). - [10] LYNEN, F.: Biosynthesis of saturated fatty acids. Fed. Proc. 20, 941 (1961). - [11] W AKIL, S. J., and J. GANGOLY: On the mechanism of fatty acid synthesis. J. Amer. chem. Soc. 81, 2597 (1959). - [12] BonTz, W., S. ABRAHaM, I. L. Chatrorf, and W. E. Dozier: Fatty acid synthesis from acetate by human liver homogenate fractions. J. elin. Invest. 41, 860 (1962). - [13] LöHz, G. W., u. H. D. WALLER:
Glucose-6-phosphat-Dehydrogenase. In: Methoden der enzymatischen Analyse (Hrsg. H. U. BeRGMEYER), p. 748 f., Wein heim: Verl. Chemie 1962. - [14] KavfMan, S., C. GILVARG, O. CORI, and S. OCHOA: Enzymatic oxidation of $\alpha$-ketoglntarate and coupled phosphorylation. J. biol. Chem. 208, 869 (1962). — [15] EGGERER, H., u. F. LYYNEN: Zur Biosynthese der Fettsäuren. II. Synthese und Figenschaften von S-MalonylCoenzym-A. Biochem. Z. 385, 540 (1962). - [16] MatsuHashI M., S. MatsuHasmi u. F. LYNEn: Zur Biosynthese der Fettsäuren. IV. Acetyl-Co-A Carboxylase aus Hefe. Biochem. Z. 340, 243 (1964).

\title{
Klinische Bedeutung der Bestimmung der Bindung von Trijodthyronin an Serumproteine mittels Dextran-Gel-Filtration ***
}

\author{
P. C. Scriba, H. G. Heinze, R. Landgraf, K. W. Freix und K. Schwarz \\ II. Medizinische Klinik der Universität München (Direktor: Prof. Dr. Dr. G. BoDECHTEL), \\ Institut und Poliklinik für physikalische Therapie und Röntgenologie der Universität München \\ (Direktor: Prof. Dr. H. von Bravnamirens)
}

Methoden zur Bestimmung der Bindung von Schilddrüsenhormonen an die Eiweißkörper des Blutes $[1-12]$ haben in zunehmendem Maße an Bedeutung für die Klinik gewonnen. Eine Methode zur gleichzeitigen Bestimmung des sog. freien und des proteingebundenen Anteils von in vitro zugesetztem L-Trijodthyronin-131 Jod $\left(\mathrm{T}_{\mathrm{s}}-131\right)$ im Serum mittels DextranGel-Filtration wurde von uns früher beschrieben [12]. Das Verfahren wurde bei Patienten mit normaler, gesteigerter und verminderter Schilddrüsenfunktion angewandt und die Ergebnisse mit den Resultaten der Bestimmung des proteingebrandenen Jods (PB $\left.{ }^{127} \mathrm{I}\right)$ nach BARK kR $[12,13]$ und der üblichen ${ }^{131}$ Jodspeicherungsteste verglichen. Damit sollte AufschluB über die korrelative klinische Wertigkeit der genannten Methoden gewonnen werden. - Für die klinische Diagnostik sind Patienten ein besonderes Problem, bei denen komplizierende Faktoren, wie ein endokriner Exophthalmus, eine vorausgegangene schilddrüsenspezifische Behandlung oder auch eine Jodapplikation (Röntgenkontrastmittel) die übliche Diagnostik erschweren oder unmöglich machen. Die Bedeutung der Methode der Dextran-Gel-Filtration [12] für die Beurteilung dieser Fälle sollte bei den hier beschriebenen Untersuchungen bestimmt werden.

\section{Methoden und Präparate}

Die Bestimmung des sog. freien und des proteingebundenen Anteils an $T_{3}{ }^{131} 1$ im Serum mittels Dextran-Gel-Filtration, die sog. Verdrängungsversuche, die Bestimmung des proteingebondenen Jods im Serum ( $\left.\mathrm{PB}^{127} \mathrm{~T}\right)$, die statistischen Methoden und die verwandten Präparate wurden früher beschrieben [12].

Die Durchführung der 131 Jodspeicherungsteste erfolgte in konventioneller Weise $[14,15]$. Das verabfolyte ${ }^{131} \mathrm{Jod}$ ist im Text dieser Arbeit der Kürze halber als ,,Dosis" bezeichnet, ein Ausdruck, der nicht mit dem in der Radiologie gebräuchlichen Dosisbegriff zu verwechseln ist. Form, Lage und Größe der Schilddrüse wurden szintigraphisch mit Hilfe eines Siemens-Nucleographen mit dem Pulszeitanalysator bestimmt. Das sog. Gesamt ${ }^{131}$ Jod wurde in $4 \mathrm{ml}$ Serum bestimmt, die Angabe erfolgt in Prozent der verabfolgten Aktivität pro

* Mit Unterstützung der Deutschen Forschungsgemeinschaft.

** Herm Prof. Dr. H. ScHwIEGK in Verehrung zum 60. Geburtstag gewidmet.
Liter Serum (Normalwert bis $0,3 \% /$ Liter). Bei bestimmter Fragestellung wurde ein Trijodthyroninsuppressionstest durch geführt. Die Patienten erhielten dabei I Woche vor dem 131.Jodspeicherungstest und während des Testes 60-80 ug

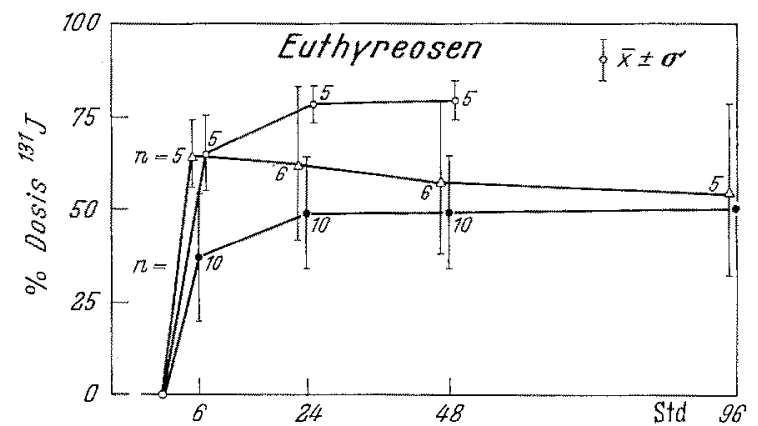

Abb. 1. Mittelwerte und Standardabweichung $(\bar{x} \pm \sigma)$ der Radiojodspeicherung bei normalen (- ) und jodaviden $(0-0)$ Euthyreosen und Fällen von besohennigtem Radiojodumsatz $(\triangle-\triangle)$

Trijodthyronin täglich per os. Zur Diagnose kompensierter toxischer Adenome exfolgte eine Szintigraphie unter Trijodthyroninbelastung. Ein sog. TSH-Test wurde zur Prüfung der Leistungsreserve der Schilddrüse oder zum Nachweis eines dekompensierten toxischen Adenoms, bei dem das durch Hemmung der Hypophyse nicht unter endogener TSHStimulierung stehende Schilddrüsengewebe wieder zur Jodspeicherung angeregt werden kann, angewandt. Üblicherweise wurden am Vorabend und am Morgen des Untersuchungstages 50 E TSH (Thyreostimulin der Firma Organon) intramuskulär injiziert. - Alle in dieser Arbeit angegebenen Diagnosen wurden wnter Berüeksichtigung des klinischen Befundes und aller zur Verfügung stehenden Laboratoriumsmethoden gestellt.

\section{Ergebnisse}

1. Schilddrüsenfunltionsdiagnostik der Euthyreose. Bei 27 ausgewählten, zum Zeitpunkt der Untersuchung euthyreotenen Patienten, die mit den zur Verfügung stehenden Methoden untersucht wurden and in Tabelle 1 zusammengefaß $\beta$ sind, fanden wir drei verschiedene Speicherungstypen beim ${ }^{131}$ Jodspeicherungstest. Zehn Fälle wiesen einen ,normalen" Speicherungsverlauf $(A b b, 1,5)$ auf, d. h. einer mittleren Jodraffung 6 Std nach ${ }^{131}$ Jodgabe von $37 \pm 17 \%$ Dosis (Mittelwert $\bar{x}$ mit Standardabweichung $\sigma$ ) folgte innerhalb von 48 Std kein Abfall der Speicherungskurve, sondern ein weiterer Anstieg der Speicherungswerte 


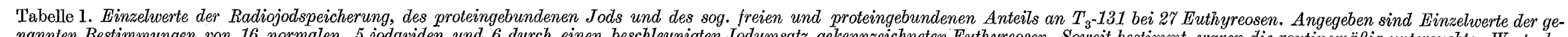
nannten Bestimmungen von 16 normalen, 5 jodaviden und 6 darch einen besching

\begin{tabular}{|c|c|c|c|c|c|c|c|c|c|c|c|c|c|c|c|c|c|c|}
\hline & \multirow{3}{*}{ Name } & \multirow{3}{*}{$\begin{array}{c}\text { Gewicht; } \\
\text { Größe }\end{array}$} & \multirow{2}{*}{\multicolumn{5}{|c|}{${ }^{131 J o d-S p e l c h e r u n g ~ i n ~ \% ~ D o s i s ~}$}} & \multirow{3}{*}{$\begin{array}{c}\text { Gesamt- } \\
\text { s:J Jod im } \\
\text { Serum naoh } \\
48 \mathrm{Std} \\
\% \text { Dosis } / 1\end{array}$} & \multirow{3}{*}{ Szintigramm } & \multirow{3}{*}{ Struma } & \multirow{3}{*}{$\begin{array}{r}\mathrm{PB}^{122} \mathrm{I} \\
\mu \mathrm{g}-\% \\
\end{array}$} & \multicolumn{6}{|c|}{ L-Trijodthyronin-181-Jod } & \multirow{3}{*}{ Bemerkungen } \\
\hline & & & & & & & & & & & & \multicolumn{2}{|c|}{ als tracer } & \multicolumn{2}{|c|}{ in $0,1 \mu \mathrm{g} / \mathrm{ml}$} & \multicolumn{2}{|c|}{ in $0,5 \mathrm{\mu g} / \mathrm{ml}$} & \\
\hline & & & $2 \mathrm{Std}$ & $6 \mathrm{std}$ & $24 \mathrm{std}$ & 48 std & $96 \mathrm{Std}$ & & & & & $\%$ geb. & $\%$ frei & $\%$ geb. & $\%$ frei & $\%$ geb. & $\%$ frei & \\
\hline \multirow{16}{*}{$\begin{array}{l}\text { Nor- } \\
\text { male }\end{array}$} & $\begin{array}{l}\text { Ba., G. } \\
52, \text { o }\end{array}$ & $\begin{array}{r}60 \\
163\end{array}$ & - & 34 & 45 & 45 & - & - & $\begin{array}{l}\text { re. keine Imp. unter } T_{3} \text {, } \\
\text { li. Imp.-Muster }\end{array}$ & - & 5,0 & $\begin{array}{l}83,6 \\
83,0\end{array}$ & $\begin{array}{l}15,1 \\
16,2\end{array}$ & $\begin{array}{l}82,8 \\
80,8\end{array}$ & $\begin{array}{l}16,5 \\
16,1\end{array}$ & $\begin{array}{c}75,9 \\
(63,4)\end{array}$ & $\begin{array}{l}21,4 \\
24,7\end{array}$ & $\begin{array}{l}\text { neg. Trijodthyronin- } \\
\text { Suppress.-Test, Ver- } \\
\text { dacht auf komp. tox.- } \\
\text { Adenom }\end{array}$ \\
\hline & $\begin{array}{l}\text { Ha. H., } \\
52, \text { o }\end{array}$ & $\begin{array}{r}80 \\
174\end{array}$ & - & 34 & 44 & 44 & - & $一$ & $\begin{array}{l}\text { homog. no. Imp.- } \\
\text { Muster }\end{array}$ & Struma diffusa & 5,8 & $\begin{array}{l}84,2 \\
83,8\end{array}$ & $\begin{array}{l}14,4 \\
15,4\end{array}$ & $\begin{array}{l}84,1 \\
83,8\end{array}$ & $\begin{array}{l}15,4 \\
15,4\end{array}$ & $\begin{array}{l}76,8 \\
75,6\end{array}$ & $\begin{array}{l}22,6 \\
23,3\end{array}$ & $\begin{array}{l}2 \times \text { Strumaresektion vor } \\
\text { Jahren }\end{array}$ \\
\hline & $\begin{array}{l}\text { Sp. F., } \\
64, \text { 우 }\end{array}$ & 55 & 15 & 27 & 45 & 47 & - & - & $\begin{array}{l}\text { kein Imp.-Muster, nur } \\
\text { tox. Adenomknoten }\end{array}$ & - & 4,8 & 80,3 & 15,7 & $\stackrel{81,2}{-}$ & $\underline{16,0}$ & $\underline{76,0}$ & 28,1 & $\begin{array}{l}\text { dekomp. tox. Adenom } \\
\text { (TSH.Test) }\end{array}$ \\
\hline & $\begin{array}{l}\text { Ba. M., } \\
36, q\end{array}$ & $\begin{array}{r}79 \\
169\end{array}$ & - & 17 & 27 & 29 & - & - & 一 & Struma diffusa & 4,4 & 81,7 & 15,5 & $\stackrel{83,1}{-}$ & 16,2 & 71,4 & 23,4 & - \\
\hline & $\begin{array}{l}\text { La. M., } \\
53,9\end{array}$ & 57 & - & 53 & 61 & 63 & - & - & $\begin{array}{l}\text { geringe retrostern. } \\
\text { Imp. - Vermehrung }\end{array}$ & Struma diffusa & 7,4 & $\begin{array}{c}82,8 \\
(88, \mathbf{1})\end{array}$ & $\begin{array}{l}16,9 \\
16,7\end{array}$ & $\begin{array}{l}83,0 \\
80,8\end{array}$ & $\begin{array}{l}19,1 \\
16,7\end{array}$ & - & $\overline{-}$ & $\begin{array}{l}\text { Diabetes mellitus, GU + } \\
23 \% \text { Gesamtcholeste- } \\
\text { rin } 270 \mathrm{mg}-\%\end{array}$ \\
\hline & $\begin{array}{l}\text { Bä. P., } \\
44, \text { ठ. }\end{array}$ & $\begin{array}{r}77 \\
174\end{array}$ & - & 20 & 34 & 33 & - & - & $\begin{array}{l}\text { re.markstekgr. homog. } \\
\text { supraclav. Imp.-Feld }\end{array}$ & - & 4,8 & $\begin{array}{l}86,3 \\
78,4\end{array}$ & $\begin{array}{l}13,6 \\
13,5\end{array}$ & $\begin{array}{l}83,2 \\
84,5\end{array}$ & $\begin{array}{l}\mathbf{1 4}, 9 \\
\mathbf{1 5 , 3}\end{array}$ & $\begin{array}{l}72,8 \\
75,2\end{array}$ & $\begin{array}{l}20,0 \\
18,4\end{array}$ & $\begin{array}{l}\text { vor } 4 \text { Mon. Strumaresek- } \\
\text { tion (Riedel-Struma) }\end{array}$ \\
\hline & $\begin{array}{l}\text { Seh. H., } \\
38, \approx\end{array}$ & $\begin{array}{r}52 \\
164\end{array}$ & - & 16 & 32 & 31 & - & - & no. Imp.-Muster & - & 5,4 & 84,4 & 11,1 & $\stackrel{88,3}{-}$ & 11,3 & $\stackrel{83,0}{-}$ & $\stackrel{15,8}{-}$ & - \\
\hline & $\begin{array}{l}\text { Gu. M., } \\
57, \text { o }\end{array}$ & $\begin{array}{r}70 \\
170\end{array}$ & - & 45 & 54 & 52 & 50 & - & $\begin{array}{l}\text { re. intens. pflaumengx. } \\
\text { Knoten, li. kaum } \\
\text { Imp. }\end{array}$ & Struma nodosa & 3,2 & $\begin{array}{l}88,7 \\
88,4\end{array}$ & $\begin{array}{l}12,0 \\
11,5\end{array}$ & $\begin{array}{l}90,4 \\
86,8\end{array}$ & $\begin{array}{l}11,9 \\
12,3\end{array}$ & $\begin{array}{l}78,9 \\
82,2\end{array}$ & $\begin{array}{l}20,7 \\
18,0\end{array}$ & $\begin{array}{l}\text { fragliche Hypothyreose } \\
\text { noch (Eu-) }\end{array}$ \\
\hline & $\begin{array}{l}\text { We. A., } \\
\text { 21, 早 }\end{array}$ & $\begin{array}{r}63 \\
173\end{array}$ & - & 69 & 77 & 79 & - & $<0,3$ & no. Imp.-Muster & $\begin{array}{l}\text { Mittellappen } \\
\text { diff. vergr. }\end{array}$ & 3,8 & $\stackrel{88,3}{-}$ & $\begin{array}{l}12,2 \\
13,3\end{array}$ & $\stackrel{89,1}{-}$ & 15,5 & $\stackrel{79,3}{-}$ & $\stackrel{21,8}{-}$ & - \\
\hline & $\underset{q}{\mathrm{KI} . \mathrm{M}}$ & - & \multicolumn{5}{|c|}{ nicht gemacht } & - & - & - & 5,4 & $\stackrel{85,9}{-}$ & $\stackrel{15,4}{-}$ & $=$ & 二 & $=$ & - & ambulante Patientin \\
\hline & $\begin{array}{l}\text { Ka. L., } \\
19, \varnothing\end{array}$ & $\begin{array}{r}61 \\
175\end{array}$ & \multicolumn{5}{|c|}{ nicht gemacht } & - & - & - & 3,8 & $\begin{array}{l}85,1 \\
85,4\end{array}$ & $\begin{array}{l}11,9 \\
11,7\end{array}$ & - & - & 二 & - & $\longrightarrow$ \\
\hline & Le. M., & - & - & - & - & - & - & - & - & - & 5,8 & $\stackrel{82,3}{-}$ & 17,1 & - & 二 & $\stackrel{76,1}{-}$ & $\underline{24,8}$ & $\begin{array}{l}\text { Mitralvitium, Vorhof- } \\
\text { flimmern }\end{array}$ \\
\hline & 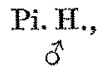 & - & - & - & - & - & - & - & - & - & 4,0 & $\begin{array}{l}79,3 \\
81,4\end{array}$ & $\begin{array}{l}17,8 \\
17,6\end{array}$ & - & - & $=$ & - & - \\
\hline & $\underset{\delta}{\operatorname{Pa} . \mathbf{I},}$ & - & - & - & - & - & - & - & 一 & - & 6,0 & $\stackrel{81,4}{-}$ & $\underline{17,8}$ & - & - & - & - & - \\
\hline & $\underset{\sigma}{\text { Ki. L., }}$ & - & - & - & - & - & - & - & 一 & - & 7,2 & $\begin{array}{l}86,7 \\
80,2\end{array}$ & $\begin{array}{l}11,4 \\
12,5\end{array}$ & - & - & - & - & - \\
\hline & $\begin{array}{l}\text { St. J., } \\
39,0\end{array}$ & 70 & - & 57 & 70 & 70 & - & - & $\begin{array}{l}\text { no. homog. epiclav. } \\
\text { Imp.-Muster }\end{array}$ & Struma diffusa & 4,0 & $\begin{array}{l}81,4 \\
87,0 \\
\end{array}$ & $\begin{array}{l}18,7 \\
17,3 \\
\end{array}$ & - & - & 二 & - & - \\
\hline $\begin{array}{l}\text { Jod- } \\
\text { avide }\end{array}$ & $\begin{array}{l}\text { Ho. T. } \\
\text { 15, } . \text {. }\end{array}$ & 二 & - & 80 & 84 & 85 & - & - & $\begin{array}{l}\text { re. + li. hühnereigx. } \\
\text { impulsdichtere } \\
\text { Bezirke }\end{array}$ & $\begin{array}{l}\text { Struma diffusa } \\
\text { et magna }\end{array}$ & 4,8 & - & - & $\stackrel{82,8}{-}$ & $\stackrel{13,4}{-}$ & $\stackrel{75,0}{-}$ & $\underline{20,0}$ & $\begin{array}{l}\text { kombiniertes Mitral- } \\
\text { vitium }\end{array}$ \\
\hline
\end{tabular}




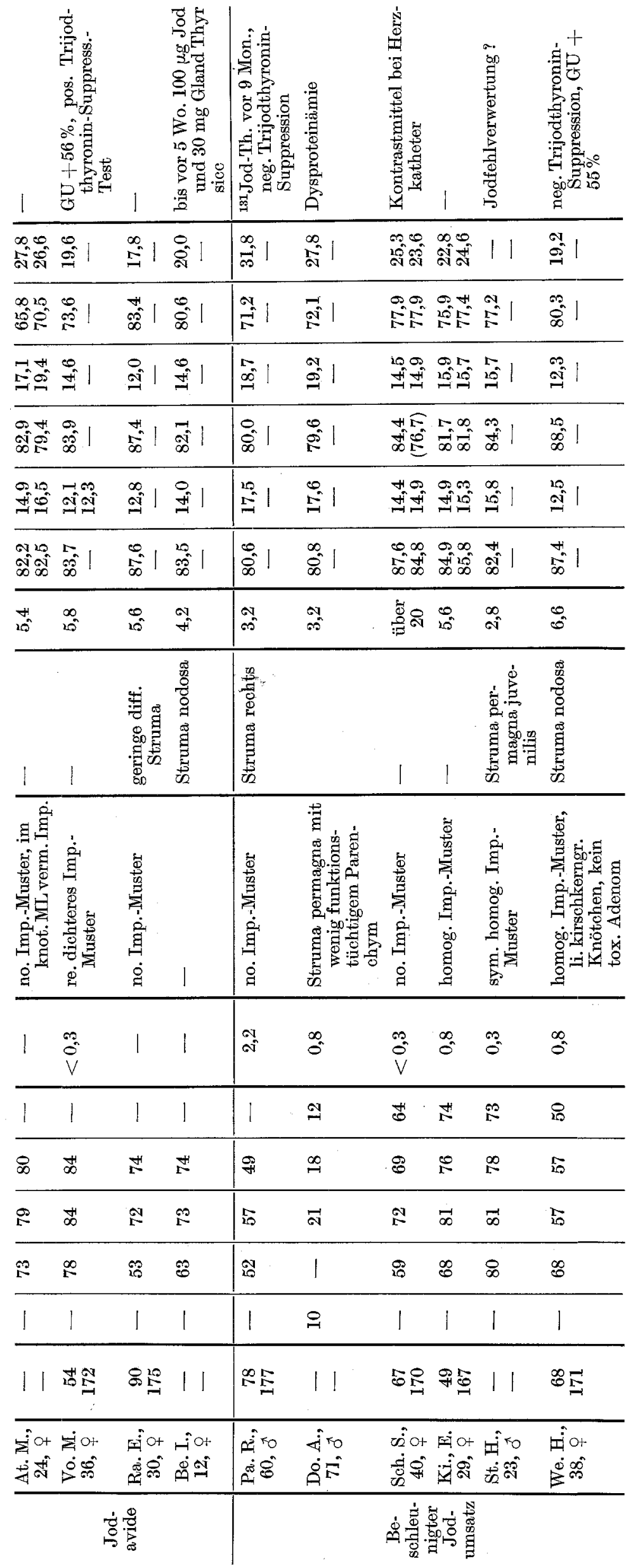

bis auf $49 \pm 16 \%$. Sechs euthyreote Patienten wiesen einen beschleunigten Radiojodumsatz auf. Sie speicherten im Mittel 6 Std nach ${ }^{131}$ Jodgabe $65 \pm 9 \%$ Dosis, nach 48 Std waren $58 \pm 21 \%$ Dosis gespeichert (Abb. 1). Bei diesen Euthyreosen mit beschleunigtem ${ }^{131}$ Jodumsatz ist das Gesamt-131Jod im Serum nach 48 Std mehr oder weniger erhöht $(0,3-2,2 \%$ Dosis je Liter, Tabelle 1$)$. Die Zahl der hier untersuchten Patienten läßt noch keinen Schluß auf die Häufigkeit des beschleunigten Radiojodumsatzes bei euthyreoten Patienten zu. Auf die Bedeutung dieses in München nicht seltenen Befundes wird in der Diskussion eingegangen. Schließlich zeigt Abb. I eine dritte Gruppe von fünf Patienten, die beim Radiojodspeicherungstest sog. hohe Plateaukurven aufwiesen. Es fand sich eine gesteigerte Jodraffung von $65 \pm 10 \%$ Dosis 6 Std nach der ${ }^{131}$ Jodgabe und anschließend ein plateauförmiger Kurvenverlauf mit Speicherungswerten von $78 \pm 5 \%$ Dosis nach 24 Std und $79 \pm 5 \%$ Dosis $(\bar{x} \pm \sigma)$ nach 48 Std. Schon nach diesen Befunden ist klar, daß es in Bayern nicht ohne weiteres möglich ist, mit Hilfe des Radiojodtestes die Euthyreose zu diagnostizieren.

Mit der Bestimmung des proteingebundenen Jods $\left(\mathrm{PB}^{127} \mathrm{I}\right)$ nach BARKER $[12,13]$ besitzen wir ein weiteres wichtiges Verfahren. zur Beurteilung der Schilddrüsenfunktion. Die in Tabelle $\mathbf{l}$ zusammengefaßten euthyreoten Patienten wiesen PB $^{127}$ T-Werte zwischen 2,8 und $7,4 \mu \mathrm{g}-\%$ auf. Der Normalbereich aller bisher untersuchten euthyreoten Patienten, berechnet als Toleranzbereich ohne Vertrauenswahrscheinlichkeit $\left(\beta_{p}=0,95, n=175\right)$, lag zwischen $3,2 \mu \mathrm{g}-\%$ und 7,2 $\mu \mathrm{g}$-\% (Abb.6). Die Patientin Sch. S. (Tabelle 1) wies einen PB ${ }^{12}$ I-Wert von über $20 \mu \mathrm{g}$ \% auf. Dabei handelte es sich entweder um eine Erhöhung durch exogenes Jod, nach einer Angiographie oder eher noch um eine einfache Jodverseuchung des Serums, wofür die normalen Speicherungswerte bei ${ }^{131}$ Jod-Speicherungstest sprachen.

Die angeführten Untersuchungsmethoden eignen sich im Idealfall gut zur Aufklärung einer normalen oder pathologischen Schilddrüsenfunktion. Eine Reihe von Störfaktoren - einerseits Jodapplikation in Form von Jodsalzen, jodhaltigen Medikamenten und vor allem von Kontrastmitteln, und der Jodmangel andererseits erschweren oft, wie schon nach der Auswertung dieser ersten Ergebnisse zu erkennen ist, die Schilddrüsenfunktionsdiagnostik mittels der „,klassischen“ Methoden. Mit der in vitro-Bestimmung des Verhältnisses von sog. freiem za proteingebundenem L-Trijodthyronin-131.Jod mit Hilfe der Dextran-Gel-Filtration [12] besitzen wir ein neues, die klinische Schilddrüsenfunktionsdiagnostik erweiterndes Verfahren. In Tabelle 1 sind die Ergebnisse der Radiojod- 
speicherungsteste und die PB ${ }^{127} \mathrm{I}-$ Werte von 27 eathyreoten Patienten mit den Werten für sog. freies und proteingebundenes $T_{3}-131$, auch im Verdrängungsversuch, verglichen. Die Mittelwerte mit der Standardabweichung $(\bar{x} \pm \sigma)$ sowie die Normalbereiche für sog. freies und proteingebundenes $T_{3}-131$ bei 27 euthyreoten Patienten sind in Tabelle 2 wiedergegeben. Man erkennt, wie schon früher beschrieben [12], daß die in der ersten Spalte angegebenen Trijodthyroninkonzentrationen zu einer relativen Verminderung des proteingebundenen und einer Vermehrung des sog. freien Anteils an $\mathrm{T}_{\mathbf{3}}$-131 führen. Dieser Verdrängungseffekt ist bei Hypothyreosen geringer und bei Hyperthyreosen etwas ausgeprägter (s. u.).

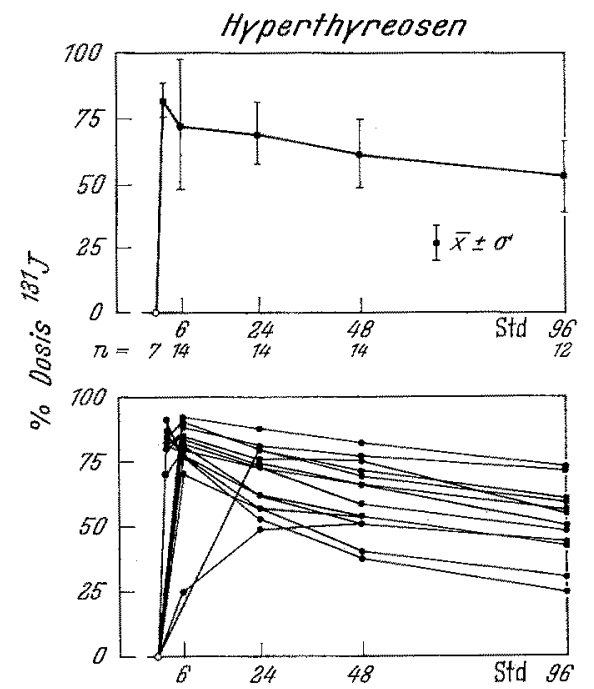

2. Schilddrïsenfunktionsdiagnostik der Hyperthy reose. Die in Tabelle 3 zusammengefaßten Patienten mit einer Schilddrüsenüberfunktion wurden von uns in zwei Gruppen eingeteilt. Wir beobachteten einmal einfache Hyperthyreosen, die z. T. bereits einmal behandelt worden waren, und andererseits szintigraphisch diagnostizierte toxische Adenome. Abb. 2 zeigt das unterschiedliche Verhalten der beiden Pa tientengruppen beim ${ }^{131}$ Jodspeicherungstest. Bei den sog. Hyperthyreosen fand sich 6 Std nach ${ }^{131}$ Jodgabe eine mittlere Speicherung von $72,4 \pm 25,6 \%$ Dosis, bei den toxischen Adenomen von $54,3 \pm 9,9 \%$ Dosis $(\bar{x} \pm \sigma)$. Man erkennt deutlich den gegenüber toxisehen Adenomen steileren Anstieg der Speicherungskurve als
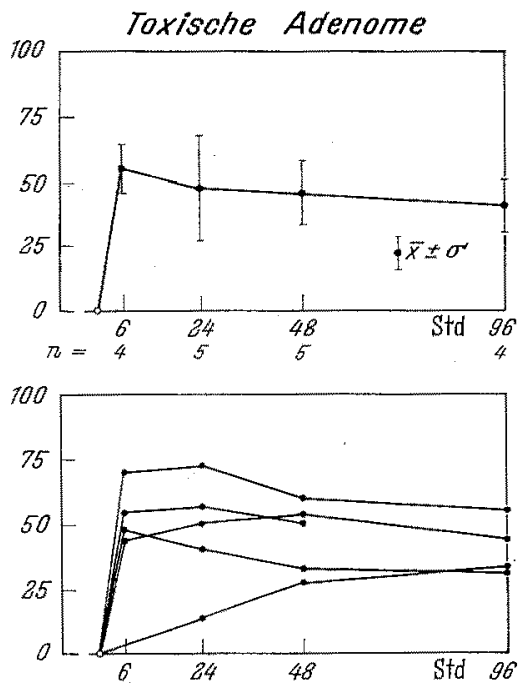

Abb. 2. Einzelwerte (unten) und Mittelwerte mit Standardabweichung $(\bar{x}+\sigma$, oben) der Radiojodspeicherung bel Hyperthyreosen (links) und toxischen Adenomen (rechts)

Doppelbestimmungen zeigen eine im allgemeinen sehr gute Reproduzierbarkeit der Werte für sog. freies und proteingebundenes $\mathrm{T}_{3}$-131. Auch bei Anwendung aller bisher erwähnter Verfahren fällt es gelegentlich schwer, sich auf eine Diagnose des Schilddrüsenfunktionszustandes festzulegen. So war z. B. bei der Patientin Gu. M. (Tabelle 1), nach der Bestimmung des $\mathrm{PB}^{122} \mathrm{I}$ and des Verhältnisses von sog. freiem zu proteingebundenem $T_{\mathrm{s}}-131$, ebenso wie nach dem klinisehen Aspekt, an das Vorliegen einer leichten Unterfunktion zu denken. Für die Einordnung zu den Euthyreosen war hier der normale Radiojodspeioherungstest und der dentliche Verdrängungseffekt von zugesetztem, nichtmarkiertem L-Trijodthyronin auf die Proteinbindung von $T_{3}-131$ aussehlaggebend. Auf die Schwierigkeit, leichte Schilddrüsenunterfunktionszustände zu diagnostizieren wird unten näher eingegangen. Die bereits erwähnte Patientin Seh. S. (Tabelle 1) war nach den Ergebnissen des Radiojodspeicherungstestes und der $\mathrm{PB}^{127 T}$-Bestimmung nicht sicher einzuordnen. Für die Diagnose stiitzten wir uns hier auf den klinischen Befund und das Ergebnis der Bestimmung des Verhältnisses von sog. freiem zu proteingebundenem $\mathrm{T}_{3}-131$. - Wie unten noch näher ausgeführt, muB bei einem sog. ,toxischen" Adenom nicht unbedingt eine Sehilddrüsenüberfunktion vorliegen. So waren die Patientinnen Ba. G. und Sp. A. trotz szintigraphisch einwandfrei nachgewiesenem ,,toxisohen" Adenom euthyreot. -Blutkörperchensenkungsgeschwindigkeit, Serumelektrophorese, Gesamteiweiß und Cholesterin wurden bei allen untersuchten Patienten routinemäBig bestimmt. Bei den Euthyreosen fand sich ein Mittelwert von $197 \pm 45 \mathrm{mg} \%$ für das Serumgesamtcholesterin. Die Serumelektrophoresen wurden ausgewertet, um wesentliche Dysproteinämien auszuschließen, da bei diesen mit Störungen der Bestimmungsmethoden für proteingebundenes Jod und für die Proteinbindung von $\mathrm{T}_{3}-131$ zu rechnen ist. Der dysproteinämische Patient Do. A. (Tabelle 1) zeigte $\mathrm{z}$. B. ein knapp normales $\mathbf{P B}^{127} \mathbf{I}$, während der proteingebundene Anteil des $\mathrm{T}_{3}-131$ an der unteren Grenze des Normalbereiches lag, so daß man eher an eine leichte therfunktion denken würde.
Tabelle 2. Mittelwerte mit Standardabweichung ( $\ddot{x} \pm \sigma)$ und Normalbereiche für sog. treies und proteingebundenes $T_{3}-131$ bei 27 Euthyreosen. Das Serum wurde mit $T_{3}-131$ bei der in der ersten Spalte der Tabelle angegebenen Gesamt-Trijodthyroninkonzentration inkubiert und der proteingebundene und der sog. treie Anteil an $T_{\text {-131 }} 131$ wie unter Methoden beschrieben, bestimmt. Die Normalbereiche sind als Toleranzbereiche ohne Vertrauenswahrscheinlichkeit $\left(\bar{x}+\bar{k}_{3} \times \sigma, \beta_{p}=0,95\right)$ angegeben $[49]$, dabei ist $k_{3}$ etwa gleich 2

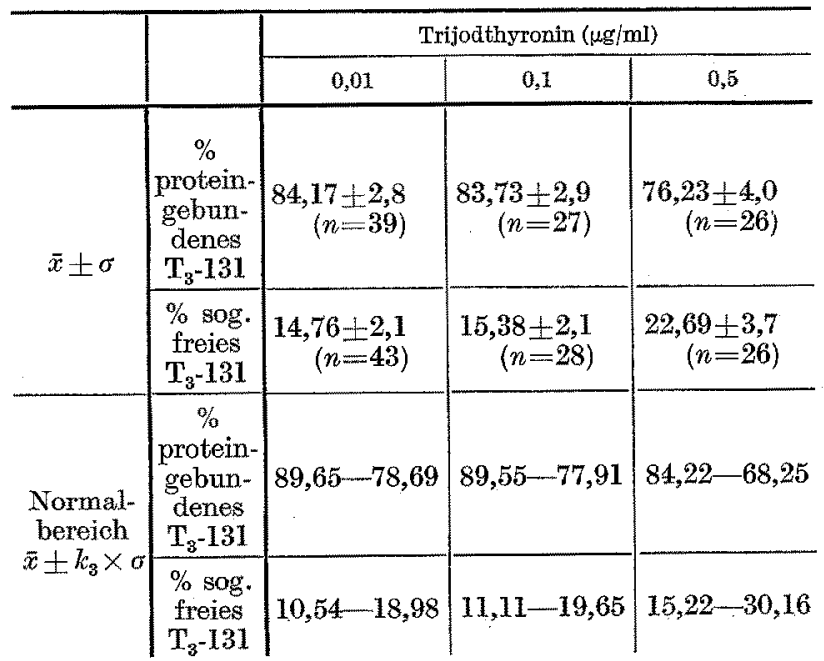

Ausdruck der gesteigerten Jodraffung bei Hyperthyreosen. Auch der intrathyreoidale Jodumsatz, erkenntlich am Kurvenabfall, war bei den hier untersuchten Hyperthyreosen größer als bei den toxischen 
Adenomen. Bei den Hyperthyreosen fand sich 96 Std nach ${ }^{131}$ Jodgabe eine mittlere Speicherung von $51,8+14 \%$ Dosis, bei den toxischen Adenomen von $40,8 \pm 9,6 \%$ Dosis. Auch das Gesamt ${ }^{131} \mathrm{Jod}$ im Serum nach 48 Std war bei den Hyperthyreosen mit 2,39 $\pm 1,2 \%$ Dosis je Liter $(\bar{x} \pm \sigma)$ gegenüber $1,6 \pm 1,1 \%$ Dosis je Liter bei den toxischen Adenomen deutlicher erhöht. Schnelle Jodraffung, beschleunigter Jodumsatz und eine Erhöhung des Gesamt-131.Jods im Serum nach 48 Std wurde bei den von uns untersuchten Hyperthyreosen praktisch immer gefunden. In unserem weiteren Beobachtungsgut fanden sich nur sehr selten echte Hyperthyreosen ohne beschleunigten Radiojodumsatz. Dabei ist allerdings zu berücksichtigen, daß der Abfall der Speicherungskurven nicht selten erst 48 bzw. 96 oder mehr Stunden nach ${ }^{131}$ Jodgabe erkennbar wurde, wie das die Patienten Sp. H., Ha. H., Ki. E., He. E., Zi. F. und Gi. T. der Tabelle 3 zeigen.

Das proteingebundene Jod ( $\left.\mathrm{PB}^{12} \mathrm{~T}\right)$ lag bei den Hyperthyreosen zwischen $7,4 \mu \sigma_{-} \%$ und Werten über $20 \mu \sigma_{-} \%$, das der toxischen Adenome zwischen 4,6 $\mu \mathrm{g}-\%$ und 14,2 $\mu \mathrm{g}-\%$. Fin erniedrigter PB $^{127}$ I-Wert von $2,2 \mu \mathrm{g}$ - $\%$ ist vermutlich auf eine thyreostatische Therapie (Patientin Ke. M., Tabelle 3) mit Favistan (1) (1-Methyl-2-mercaptoimidazol) zurüokzuführen. Extrem hohe Werte des PB ${ }^{127} \mathrm{I}$ (über $20 \mu \mathrm{g}-\%$ ) sind immer verdächtig auf eine exogene Jodzufuhr. Solche Werte sind dann unter Umständen mit einer unerwartet niedrigen ${ }^{131}$ Jodspeicherung gekoppelt (Patient Da. M., Tabelle 3).

Die Bestimmung des Verhältnisses von sog. freiem zu proteingebundenem L-Trijodthyronin-131 Jod (Tabelle 3 und 4) zeigt, daB sowohl bei Hyperthyreosen als auch bei toxischen Adenomen der proteinge. bundenè Anteil an $\mathrm{T}_{3}-131$ erniedrigt und der sog. freie Anteil erhöht ist. Auch hier ist der Unterschied zwischen Hyperthyreosen and toxischen Adenomen erkenntlich. Die Erhöhung des Anteils an sog. freien. $\mathrm{T}_{3}$-131 im Vergleich zum Normalbereich euthyreoter Patienten (Tabelle 2) ist bei den Hyperthyreosen im Mittel ausgeprägter als bei den toxischen Adenomen. In die Gruppe der toxischen Adenome sind nur jene Patienten aufgenommen worden, bei denen eine echte Cberfunktion der Schilddrüse vorlag. Die szintigraphische Diagnose des toxischen Adenoms trifft vor allem beim sog. kompensierten toxischen Adenom gelegentlich Fälle, bei denen lediglich ein gegenüber dem umgebenden Schilddrüsengewebe überaktiver Knoten und keine "Thyreotoxikose" vorliegt.

Das Serumgesamteiweiß war bei Hyperthyreosen mit $7,38 \pm 0,97 \mathrm{~g}-\%(\mathrm{n}=10)$ gegenüber dem. Serumgesamteiweiß der euthyreoten Patienten von $7,99+0,27 \mathrm{~g} \%(\mathrm{n}=22)$ etwas erniedrigt. Bei den Hyperthyreosen fand sioh ein Serumgesamtcholesterin von $159 \pm 41,0 \mathrm{mg}-\% \quad(\mathrm{n}=11, \vec{x} \pm \sigma)$. Die Cholesterinwerte überlappen deutlich mit denen der Euthyreose, so daB dieser Bestimmung im Einzelfall wenig Bedeutung für die Diagnostik zukommt ${ }^{16}$. - Proteingebundenes Jod (PB'127) und sog. freier bzw. proteingebundener Anteil an $\mathrm{T}_{3}$-131 waren bei den von uns untersuchten Hyperthyreosen korreliert (Abb. 3); der Korrelationskoeffizient $(r)$ betrug $-0,81$ bzw. $+0,79$. Für die Gruppen der euthyreoten und der hypothyreoten Patienten konnten wir keine Korrelation dieser Werte nachweisen. Das liegt möglicherweise an der kleinen Zahl der untersuchten Patienten. Trägt man alle im Rahmen dieser Untersuchung bestimmten Werte für $\mathrm{PB}^{127} \mathrm{I}$ und sog. freies bzw. proteingebundenes $T_{3}-131$ auf und berechnet den Korrelationskoeffizienten, so ergibt sich ein Wert von $r=0,61$, der einer schwachen Korrelation entspricht.

3. Schilddrüsenfunktionsdiagnostik der Hypothyreose. In der Tabelle 5 sind 17 Patienten mit einer Schilddrüsenunterfunktion zusammengefaßt. Die ${ }^{131}$ Jodspeicherungsteste (Abb.4) zeigen eine im Mittel deut- lich verminderte 131Jodspeicherung und in einigen Fällen einen beschleunigten ${ }^{131}$ Jodumsatz. Die Werte für proteingebundenes Jod ( $\left(\mathrm{PB}^{127} \mathrm{I}\right)$ von 40 früher untersuchten Hypothyreosen (Abb. 6) lagen im Mittel
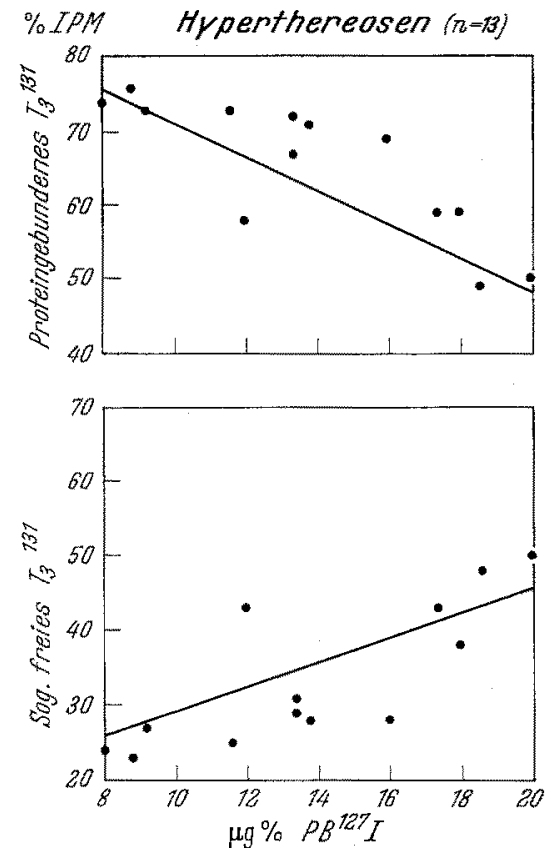

Abb. 3. Beziehungen zwischen dem proteingebundenen Jod $\left(\mathrm{PB}^{127} \mathrm{I}\right.$, Abszissen) und dem Anteil an proteingebundenem (oben) und sog. freiem (unten) $\mathrm{T}_{3^{-1}} 131$ bej 13 Hyperthyreosen. Die Berechnung der Regressionsgeraden und der Korrelationskoeffizienten erfolgt nach ${ }^{49}$

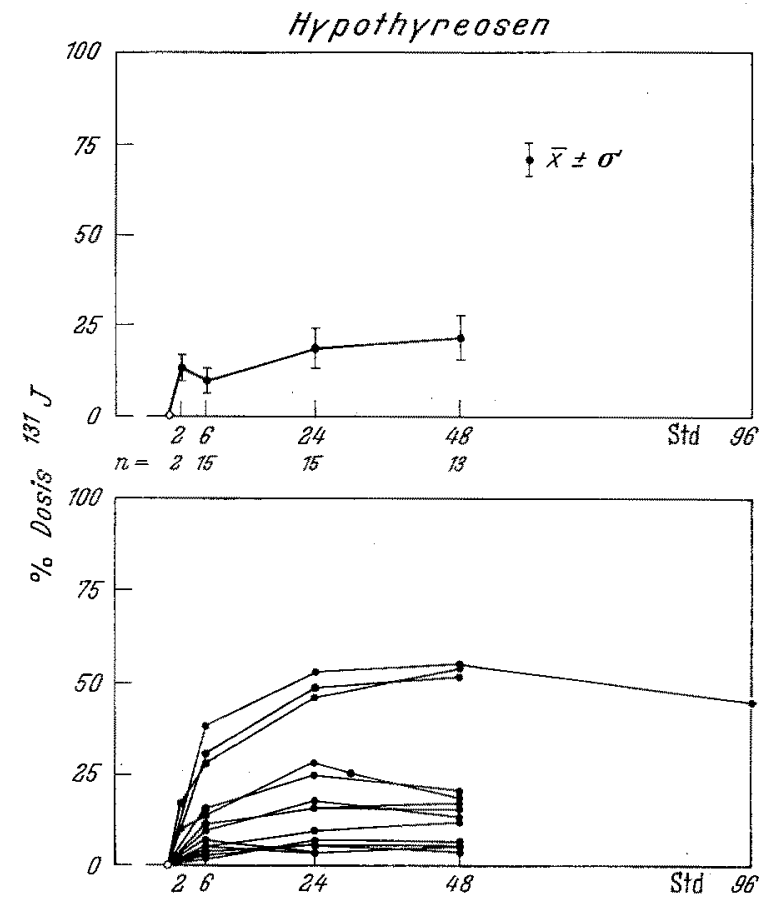

Abb. 4. Einzelwerte (unten) und Mittelwerte mit standardabweichung $(\bar{x} \pm \sigma$, oben) der Radiojodspeicherung bei Hypothyroosen

bei $2,33 \pm 0,97 \mu \mathrm{g}-\% \quad(\bar{x} \pm \sigma)$. Die Bestimmung des Verhältnisses von sog. freiem zu proteingebundenem L-Trijodthyronin-131Jod erbrachte bei den Hypothyreosen die in Tabelle 6 zusammengefaBten Ergebnisse. Es zeigt sich einmal, daß das Verhältnis von sog. freiem zu proteingebundenem $T_{3}-131$, wenn dieses in ,"tracer"-Dosen dem Inkubationsgemisch zugesetzt 
Tabelle 3

Einzelwerte der Radiojodspeicherung, des proteingebundenen Jods und des sog. Freien und proteingebundenen Anteils an L-Trijodthyronin-131.Jod bei Hyperthyreosen. Dargestellt sind Einzelwerte der oben genannten Bestimmungen von 9 Patienten mit Hyperthyreose, 7 Patienten mit bereits einmal, aber noch nicht ausreichend behandelter Hyperthyreose und 5 toxischen Aden routinemäßjig untersuchte BKS, das Serumgesamteiweiß, die Serumelektrophorese und das Serumgesamtcholesterin waren, wenn nicht anders vermerkt, nicht wesentlich pathologisch verändert

\begin{tabular}{|c|c|c|c|c|c|c|c|c|c|c|c|c|c|c|c|c|c|c|c|}
\hline & \multirow{3}{*}{ Name } & \multirow{3}{*}{$\begin{array}{c}\text { Ge- } \\
\text { wicht, } \\
\text { Grobe }\end{array}$} & \multirow{2}{*}{\multicolumn{5}{|c|}{${ }^{131}$ Jod-Speicherung in \% Dosis }} & \multirow{3}{*}{$\begin{array}{c}\text { Gesamt- } \\
\text { 1s1Jod in } \\
\text { Serum nach } \\
48 \text { Std } \\
\% \text { Dosis } / 1\end{array}$} & \multirow{3}{*}{$\begin{array}{l}\text { L-Trijod- } \\
\text { thyronin- } \\
\text { Suppres- } \\
\text { sion }\end{array}$} & \multirow{3}{*}{ Szintigramm } & \multirow{3}{*}{ Struma } & \multirow{3}{*}{$\begin{array}{l}\mathrm{PB}^{12 \eta \mathrm{T}} \\
\mu \mathrm{g}-\% \\
\end{array}$} & \multicolumn{6}{|c|}{ L-Trijodthyronin-202 Jod } & \multirow{3}{*}{ Bemerkungen } \\
\hline & & & & & & & & & & & & & \multicolumn{2}{|c|}{ als tracer } & \multicolumn{2}{|c|}{ in $0,1 . \mu \mathrm{g} / \mathrm{ml}$} & \multicolumn{2}{|c|}{ in $0,5 \mathrm{~kg} / \mathrm{ml}$} & \\
\hline & & & 2 Std & $6 \mathrm{std}$ & $24 \mathrm{Std}$ & $48 \mathrm{std}$ & $96 \mathrm{std}$ & & & & & & $\%$ geb. & $\%$ frel & $\%$ seb. & $\%$ frei & $\%$ geb. & $\%$ frei & \\
\hline \multirow{9}{*}{$\begin{array}{l}\text { Hyper- } \\
\text { thyre- } \\
\text { osen }\end{array}$} & $\begin{array}{l}\text { Si. F., } \\
58, \tilde{8}\end{array}$ & - & \multicolumn{5}{|c|}{ nicht gemacht } & 一 & - & - & - & 11,6 & $\stackrel{73,0}{-}$ & $\stackrel{24,6}{-}$ & $\overline{-}$ & - & 二 & - & maligner Exophthalmus \\
\hline & $\begin{array}{l}\text { Tr. A. } \\
45, q\end{array}$ & - & 91 & 77 & 53 & 38 & 25 & 4,3 & - & $\begin{array}{l}\text { epiclav. Struma homog. } \\
\text { Imp.-Muster }\end{array}$ & $\begin{array}{l}\text { Struma a } \\
\text { diffusa }\end{array}$ & 13,4 & $\begin{array}{l}67,8 \\
65,6\end{array}$ & $\begin{array}{l}24,8 \\
37,0\end{array}$ & $\begin{array}{l}65,8 \\
59,2\end{array}$ & $\begin{array}{l}36,5 \\
35,7\end{array}$ & $\begin{array}{l}61,3 \\
64,3\end{array}$ & $\begin{array}{l}45,6 \\
46,4\end{array}$ & Exophthalmus \\
\hline & $\begin{array}{l}\text { Je. E., } \\
\mathbf{4 4}, \phi\end{array}$ & $\stackrel{55}{-}$ & - & 84 & 74 & 66 & 57 & 2,2 & 一 & $\begin{array}{l}\text { kleines supraclav. } \\
\text { Imp.-Muster }\end{array}$ & $\begin{array}{c}\text { kleine } \\
\text { Struma }\end{array}$ & 17,4 & $\begin{array}{l}57,8 \\
59,4\end{array}$ & $\begin{array}{l}39,6 \\
44,3\end{array}$ & $\begin{array}{l}52,6 \\
56,7\end{array}$ & $\begin{array}{l}41,1 \\
43,4\end{array}$ & $\begin{array}{l}45,2 \\
42,9\end{array}$ & $\begin{array}{l}51,5 \\
50,5\end{array}$ & $\begin{array}{l}\text { Grundumsatz }+63 \% \text {, er- } \\
\text { hebliche Gewichts- } \\
\text { abnahme }\end{array}$ \\
\hline & $\begin{array}{l}\text { Sp. } \\
\mathbf{4 4}, \text {, } \\
\end{array}$ & - & 82 & 85 & - & - & - & - & - & - & $\begin{array}{l}\text { Struma } \\
\text { bes. re. }\end{array}$ & $\begin{array}{l}\text { über } \\
20\end{array}$ & $\begin{array}{l}50,8 \\
49,8\end{array}$ & $\begin{array}{l}48,8 \\
51,8\end{array}$ & $\begin{array}{l}45,8 \\
46,6\end{array}$ & $\begin{array}{l}49,2 \\
42,1\end{array}$ & 43,9 & - & Jodsalze! \\
\hline & $\begin{array}{c}\mathrm{Ha} . \mathrm{H} . \\
30,+\end{array}$ & $\begin{array}{r}56 \\
172\end{array}$ & - & 92 & 88 & 82 & 73 & 0,9 & - & $\begin{array}{l}\text { geringgradig vergr. } \\
\text { Schilddrïse }\end{array}$ & $\begin{array}{l}\text { Struma } \\
\text { diffusa }\end{array}$ & 13,8 & $\begin{array}{l}69,8 \\
71,8\end{array}$ & $\begin{array}{l}28,8 \\
27,5\end{array}$ & 67,9 & $\underline{33,2}$ & $\begin{array}{l}56,2 \\
56,3\end{array}$ & $\begin{array}{l}45,1 \\
42,6\end{array}$ & - \\
\hline & $\begin{array}{l}\text { Wo. R., } \\
59, \sigma^{-}\end{array}$ & $\begin{array}{r}71 \\
170\end{array}$ & 77 & 76 & 62 & 51 & 44 & 3,1 & - & $\begin{array}{l}\text { homog. Imp.-Muster, } \\
\text { li. cranial. min. Imp. }\end{array}$ & $\begin{array}{c}\text { Struma } \\
\text { nodosa } \\
\text { beidseits }\end{array}$ & 8,8 & 75,5 & $\underline{22,5}$ & $\stackrel{75,9}{-}$ & $\stackrel{23,7}{-}$ & $\underline{67,0}$ & $\underline{33,2}$ & $\begin{array}{l}\text { Exophthalmus, Dys- } \\
\text { proteinämie (Leber- } \\
\text { parenchymsohaden) }\end{array}$ \\
\hline & $\begin{array}{l}\text { Wi. P., } \\
9, \text { \% }\end{array}$ & $\begin{array}{r}35 \\
140\end{array}$ & 87 & 78 & 62 & 54 & - & 4,6 & - & $\begin{array}{l}\text { homog. großes Imp.- } \\
\text { Muster }\end{array}$ & $\begin{array}{c}\text { Struma } \\
\text { magna }\end{array}$ & 12,0 & $\stackrel{57,8}{-}$ & $\stackrel{42,8}{-}$ & $\stackrel{53,8}{-}$ & $\stackrel{47,0}{-}$ & $\stackrel{47,4}{-}$ & 53,0 & $\begin{array}{l}\text { Exophthalmus, Dys- } \\
\text { proteinämie }\end{array}$ \\
\hline & $\begin{array}{c}\text { So. M., } \\
42, q\end{array}$ & $\begin{array}{r}56 \\
161\end{array}$ & 85 & 90 & 80 & 71 & 61 & 2,6 & - & $\begin{array}{l}\text { homog. Imp.-Muster, } \\
\text { re. Lappen vergr. }\end{array}$ & $\begin{array}{c}\text { Struma } \\
\text { nodosa }\end{array}$ & 13,4 & $\begin{array}{l}70,0 \\
72,9\end{array}$ & $\begin{array}{l}29,0 \\
29,8\end{array}$ & $\begin{array}{l}69,9 \\
68,3\end{array}$ & $\begin{array}{l}28,9 \\
30,8\end{array}$ & $\begin{array}{l}64,8 \\
65,1\end{array}$ & $\begin{array}{l}31,0 \\
34,8\end{array}$ & - \\
\hline & $\begin{array}{l}\text { Ki. E., } \\
\text { O+24, }\end{array}$ & 46 & 70 & 82 & 73 & 66 & 51 & 1,6 & - & $\begin{array}{l}\text { homog. no. Imp.- } \\
\text { Muster }\end{array}$ & - & 16,0 & $\stackrel{69,0}{-}$ & $\underline{28,3}$ & $\frac{69,5}{-}$ & $\frac{30,8}{-}$ & 63,3 & $\stackrel{35,6}{-}$ & Exophthalmus \\
\hline \multirow{7}{*}{$\begin{array}{c}\text { Hyper- } \\
\text { thyre- } \\
\text { osen } \\
\text { trotz } \\
\text { Thera- } \\
\text { pie }\end{array}$} & $\begin{array}{c}\text { Mü. E., } \\
56, q\end{array}$ & - & - & 80 & 73 & 59 & 49 & 2,5 & neg. & $\begin{array}{l}\text { kl. retrosternales Imp. } \\
\text { Muster }\end{array}$ & - & 7,4 & $\overline{73,7}$ & $\begin{array}{l}23,4 \\
24,8\end{array}$ & $\begin{array}{l}68,7 \\
66,2\end{array}$ & $\begin{array}{l}30,3 \\
25,2\end{array}$ & $\begin{array}{l}63,5 \\
67,2\end{array}$ & $\begin{array}{l}33,3 \\
36,6\end{array}$ & $\begin{array}{l}\text { Rest-Thyreotoxikose nach } \\
{ }^{131} \text { Jod-Th. vor }{ }^{1} / 2 \mathrm{Jahr}\end{array}$ \\
\hline & $\begin{array}{r}\text { Fi. M., } \\
68, q\end{array}$ & $\begin{array}{r}70 \\
165\end{array}$ & - & 89 & 80 & 70 & 60. & 3,3 & - & $\begin{array}{l}\text { kl. epiclav. Imp.- } \\
\text { Muster }\end{array}$ & - & 9,2 & $\begin{array}{l}72,3 \\
73,4\end{array}$ & $\begin{array}{l}24,7 \\
29,2\end{array}$ & $\begin{array}{l}66,0 \\
64,8\end{array}$ & $\begin{array}{l}33,8 \\
32,7\end{array}$ & $\begin{array}{l}51,5 \\
52,3\end{array}$ & $\begin{array}{l}48,2 \\
47,2\end{array}$ & $\begin{array}{l}\text { vor } 1 \text { Mon. Cholecysto- } \\
\text { graphie bis vor } 2 \text { Mon., } \\
\text { Irenat, Herzinsuff. }\end{array}$ \\
\hline & $\begin{array}{l}\text { Sch. I., } \\
52, \stackrel{+}{+}\end{array}$ & $\begin{array}{r}56 \\
153\end{array}$ & 81 & 84 & 76 & 76 & - & 1,4 & - & $\begin{array}{l}\text { sym. epiclav. vergx. } \\
\text { Imp.-Muster }\end{array}$ & $\begin{array}{l}\text { Struma } \\
\text { diffusa }\end{array}$ & 18,0 & $\stackrel{59,1}{-}$ & $\stackrel{37,8}{-}$ & $\stackrel{61,1}{-}$ & $\stackrel{38,6}{-}$ & $\stackrel{42,4}{-}$ & $\stackrel{57,4}{-}$ & $\begin{array}{l}\text { 131.Jod-Th. vor } 4 \text { Mon., } \\
\text { Exophthalmus }\end{array}$ \\
\hline & $\begin{array}{c}\text { Br. E., } \\
57,8\end{array}$ & $\begin{array}{r}60 \\
162\end{array}$ & - & 70 & 57 & 54 & 43 & 1,6 & 一 & $\begin{array}{l}\text { re. Lappen kindsfaust- } \\
\text { groß, li. Lappen } \\
\text { markstckgr. Imp. }\end{array}$ & $\begin{array}{l}\text { Struma } \\
\text { nodosa }\end{array}$ & 18,6 & $\begin{array}{l}48,1 \\
49,4 \\
-\end{array}$ & $\begin{array}{l}47,8 \\
47,5 \\
-\end{array}$ & $\begin{array}{l}48,2 \\
49,1 \\
49,2\end{array}$ & $\begin{array}{l}49,3 \\
46,8 \\
49,8\end{array}$ & $\begin{array}{l}47,2 \\
47,7 \\
\end{array}$ & $\begin{array}{l}52,8 \\
53,2 \\
-\end{array}$ & $\begin{array}{l}\text { leichter Exophthalmus, } \\
\text { Strumareseltion } 1947\end{array}$ \\
\hline & $\begin{array}{c}\text { Ke. M., } \\
63, q\end{array}$ & $\begin{array}{r}37 \\
168\end{array}$ & - & - & 81 & 77 & 72 & 0,6 & - & $\begin{array}{l}\text { re. gänseei., li. hühner- } \\
\text { eigr. Imp.-Muster, } \\
\text { Isthmns intens. Imp. }\end{array}$ & $\begin{array}{l}\text { Struma } \\
\text { nodosa }\end{array}$ & $(2,2)$ & $\begin{array}{l}(74,6) \\
(63,6)\end{array}$ & $\begin{array}{l}26,1 \\
26,4\end{array}$ & $\begin{array}{l}75,0 \\
72,4\end{array}$ & $\begin{array}{l}32,5 \\
28,8\end{array}$ & $\begin{array}{l}57,3 \\
55,7\end{array}$ & $\begin{array}{l}41,0 \\
53,5\end{array}$ & $\begin{array}{l}\text { niedriges PB }{ }^{127} \mathrm{I} \text { (Favistan- } \\
\text { Th.) klinisch: Hyper- } \\
\text { thyreose }\end{array}$ \\
\hline & $\begin{array}{c}\text { Kn. F., } \\
58, \%\end{array}$ & $\begin{array}{r}55 \\
164\end{array}$ & - & 78 & 57 & 40 & 31 & 3,5 & - & $\begin{array}{l}\text { homog. vergr. Imp.- } \\
\text { Muster }\end{array}$ & $\begin{array}{l}\text { Struma } \\
\text { diffusa }\end{array}$ & 12,8 & $\stackrel{64,2}{-2}$ & $\stackrel{35,0}{-}$ & $\stackrel{62,6}{-}$ & 36,5 & $\stackrel{61,3}{-}$ & $\stackrel{43,3}{-}$ & $\begin{array}{l}\text { Exophthalmus } \\
2 \times{ }^{131 J o d-T h}\end{array}$ \\
\hline & $\begin{array}{c}\text { Da. M., } \\
44, \frac{.}{q}\end{array}$ & $\begin{array}{r}46 \\
168\end{array}$ & - & 24 & 49 & 51 & - & 0,24 & - & $\begin{array}{l}\text { re. hühnereigr., li. } \\
\text { markstckgr. Imp.- } \\
\text { Muster }\end{array}$ & $\begin{array}{c}\text { Struma } \\
\text { nodasa }\end{array}$ & $\begin{array}{c}\text { über } \\
20\end{array}$ & 77,2 & 20,2 & $\begin{array}{l}75,9 \\
-\end{array}$ & $\underline{21,9}$ & $\underline{67,2}$ & 31,2 & $\begin{array}{l}\text { Strumaresektion } 1954, \\
\text { exog. Jodzufuhr, GU + } \\
25 \% \text {, leichte Hyperth.? }\end{array}$ \\
\hline
\end{tabular}




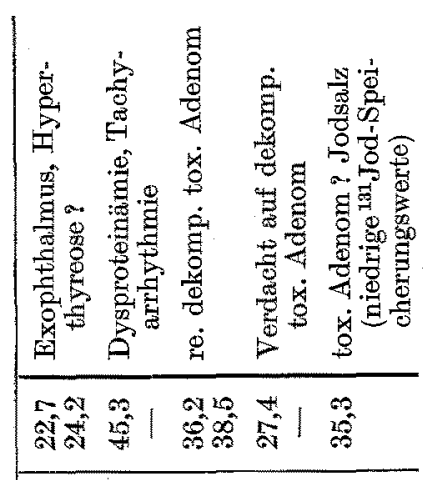

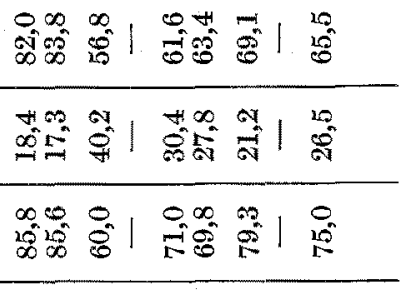

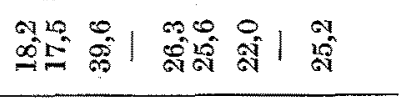

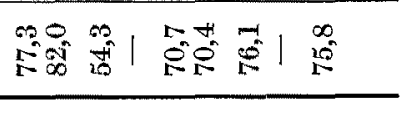

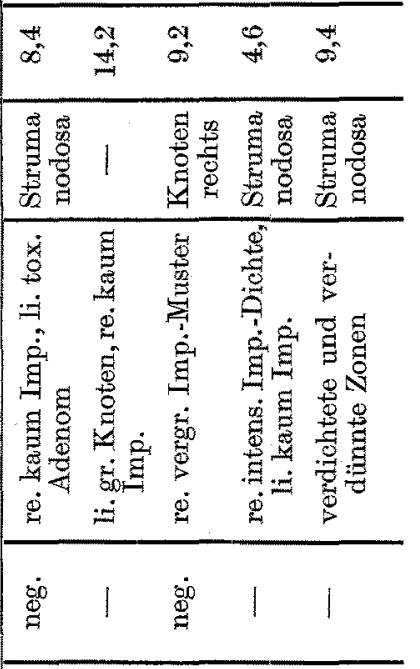

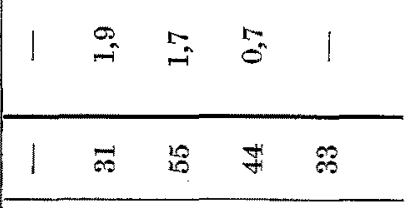

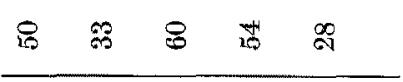

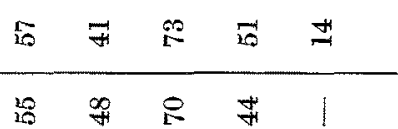

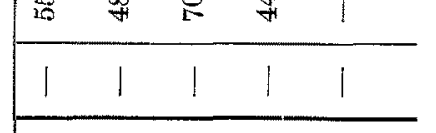

\begin{tabular}{|c|c|c|c|}
\hline \multirow{2}{*}{\multicolumn{4}{|c|}{ 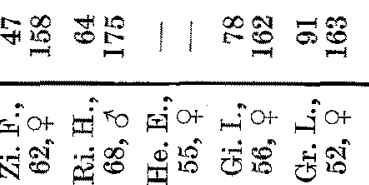 }} \\
\hline & & & \\
\hline
\end{tabular}

wurde, nicht sehr verschieden von dem der Euthyreosen war. Andererseits ist bei Hypothyreosen die Verdrängung von $\mathrm{T}_{3}-131$ bei Zusatz von nichtmarkiertem L-Trijodthyronin geringer als im Serum von euthyreoten Patienten. Auf die Bedeutung dieses Befundes für die Differentialdiagnose wird noch eingegangen.

Die Speicherungswerte des Patienten Wa.H. (Tabelle 5) sind in Abb. 4 nicht berücksichtigt. Es handelte sich um eine enorm gesteigerte Jodraffung mit hohem plateauförmigem Verlauf. Zum AusschluB einer Jodfehlverwertung bzw. eines Peroxydasemangels wurden $1200 \mathrm{mg}$ Natriumperchlorat (Irenat ${ }^{\circledR}$ ) 24 Std nach ${ }^{131}$ Jodgabe verabreicht. Der bei einem Peroxydasemangel zu erwartende rasche Radioaktivitätsabfall über der Schilddrüse blieb aus. Bei der ausgeprägten Struma, der hohen Jodspeicherung, dem niedrigen $\mathrm{PB}^{127} \mathrm{I}$. Wert und der hohen T $\mathrm{T}_{3}$-131.Proteinbindung halten wir das Vorliegen einer anderen Form einer Jodfehlverwertung für möglich. Funktionell bestand eine Hypothyreose. - Bei drei der hypothyreoten Patienten (E..K., Seh. A. und Pe. L., Tabelle 5) fanden sich etwa normale ${ }^{131}$ Jodspeicherungskurven. In der Diskussion wird auf das in Jodmangelgebieten

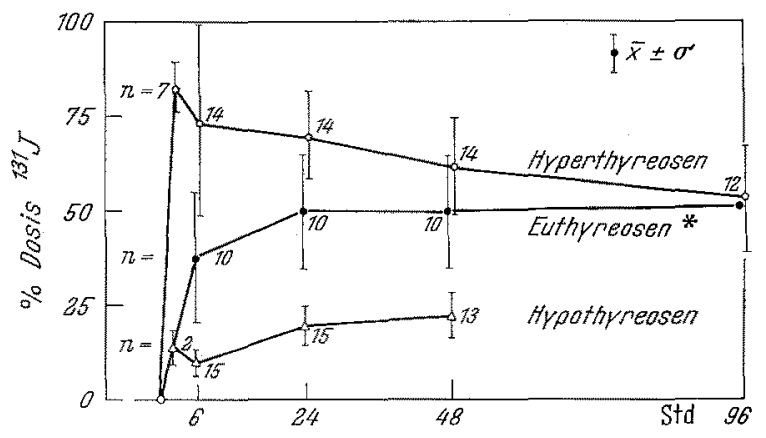

Abb. 5. Mittelwerte und Standardabweichung $(\bar{x} \pm \sigma)$ der Radiojodspeieherung bei Hyperthyreosen $(O-O)$, Futhyreosen* ( - ) und Hypothyreosen ( $\triangle-\Delta$ ). Dargestellt sind die Mittelwerte von 14 Hyperthyreosen, 15 Hypothyreosen und 10 Duthyreosen. Bei den Futhyreosen* wurden die Falle mit Jodavidität oder besehleunigtem Jodumsatz ( $\mathrm{vgl}$. Abb. 1) nicht berücksichtigt

Tabelle 4. Mittelwerte und Standardabweichung $(\bar{x} \pm \sigma)$ für sog. freies und proteingebundenes $T_{3}-131$ bei Hyperthyreosen und toxischen Adenomen

\begin{tabular}{|c|c|c|c|c|}
\hline & & \multicolumn{3}{|c|}{ Trijodthyronin $(\mu \mathrm{g} / \mathrm{ml})$} \\
\hline & & 0,01 & 0,1 & 0,5 \\
\hline \multirow{2}{*}{$\begin{array}{c}\text { Hyper- } \\
\text { thyreasen }\end{array}$} & $\begin{array}{l}\% \text { protein- } \\
\text { gebundenes } \\
\mathrm{T}_{3}-131\end{array}$ & $\begin{array}{r}65,26 \pm 9,0 \\
(n=\mathbf{2 4}) \\
\end{array}$ & $\begin{array}{c}62,13 \pm 9,5 \\
(n=24)\end{array}$ & $\begin{array}{r}56,13 \pm 8,5 \\
(n=23)\end{array}$ \\
\hline & $\begin{array}{l}\% \text { sog. } \\
\text { freies } \\
\mathrm{T}_{3} 131\end{array}$ & $\begin{array}{r}32,91 \pm 9,4 \\
(n=25)\end{array}$ & $\begin{array}{c}33,38 \pm 12,8 \\
(n=24)\end{array}$ & $\begin{array}{r}43,50 \pm 7,8 \\
(n=22)\end{array}$ \\
\hline \multirow{2}{*}{$\begin{array}{l}\text { Toxische } \\
\text { Adenome }\end{array}$} & $\begin{array}{c}\% \text { protein- } \\
\text { gebundenes } \\
\mathrm{T}_{3}-131\end{array}$ & $\begin{array}{c}72,44 \pm 8,0 \\
(n=7)\end{array}$ & $\begin{array}{c}75,21 \pm 8,6 \\
(n=7)\end{array}$ & $\begin{array}{c}68,89 \pm 9,5 \\
(n=7)\end{array}$ \\
\hline & $\begin{array}{l}\% \text { sog. } \\
\text { freies } \\
\mathrm{T}_{8}-131\end{array}$ & $\begin{array}{c}24,91 \pm 6,8 \\
(n=7)\end{array}$ & $\begin{array}{c}25,97 \pm 7,4 \\
(n=7)\end{array}$ & $\begin{array}{c}32,80 \pm 7,7 \\
(n=7)\end{array}$ \\
\hline
\end{tabular}

häufig komplizierte Verhältnis zwischen Höhe der ${ }^{131}$ Jodspeicherung und Schilddrüsenfunktion noch eingegangen werden. - Die Patientin Utb. C. (Tabelle 5) wies einen infolge einer 5 Tage vorher durchgeführten Cholecystographie auf über $20 \mu \mathrm{g}-\%$ erhöhten $\mathrm{PB}^{127} \mathrm{~T}$. Wert auf. Sie hatte ebenso wie der Patient Fr. F. (Tabelle 5), der mit Thyreoidea sicca behandelt worden war und vermutlich daher einen auf $6,2 \mu \mathrm{g}-\%$ erhöhten PB $^{127}$. Wert hatte, eine eindeutige Hypothyreose. - Das Serumgesamteiweiß war bei den hypothyreoten Patienten mit 8,34 $\pm 0,75 \mathrm{~g}-\%(n=10, \tilde{x} \pm \sigma)$ gegenüber den Euthyreosen $(7,99 \pm$ $0,27 \mathrm{~g}-\%$ ) etwas erhöht. Die $\beta$-Globuline entsprachen mit $14,2 \pm 1,2$ rel. $\%$ bei den Hypothyreosen denen der Enthyreosen $(14,0 \pm 1,2$ rel. $\%)$. Das erhöhte Serumgesamt. cholesterin der Hypothyreosen lag im Mittel $(\tilde{x} \pm \sigma)$ bei $309 \pm 83 \mathrm{mg}-\% \quad(n=12)$.

4. Vergleich der verschiedenen Verfahren der Schilddrïsenfunktionsdiagnostik. Vergleicht man die Untersuchungsergebnisse der euthyreoten, hyperthyreoten und hypothyreoten Patienten, so fällt bei Betrachtung der Jodspeicherungsteste $(A b b .5)$ die allgemein bekannte Tatsache auf, daß die Radiojodspeicherung bei Hyperthyreosen, ebenso wie der Umsatz im allgemeinen erhöht ist. Die Hypothyreosen weisen niedrige ${ }^{131}$ Jodspeicherungswerte auf, dazwischen liegen die Euthyreosen. Diese sind in Abb. 5 mit einem Stern versehen, es handelt sich nämlich um , ausgewählte Normalfälle 6 . Im vorangehenden wurde bereits daraufhingewiesen, daß bei den euthyreoten Patienten in etwa der Hälfte der hier untersuchten Fälle ein beschleunigter Jodumsatz oder eine sog. hohe Plateaukurve zu finden war ( $\mathrm{Abb} .1$ ). Man muB in München wie in anderen Jodmangelgebieten bekanntlich mit besonderen Schwierigkeiten für den '131 Jodspeicherungstest 
Tabelle 5. Einzelwerte der Radiojodspeicherung, des proteingebundenen Jods und des sog. freien und proteingebundenen L-Trijodthyronin-131Jod bei Hypothyreosen. Die Einzelwerte der genannten Bestimmungen von 17 hypothyreoten Patienten sind angegeben; die routinemäßig untersuchte BKS und Serumelektrophorese sowie das Servmgesamteiweiß waren, soweit nicht anders vermerkt, nicht wesentlich pathologisch verändert. Die Werte des mit einer eckigen Klammer versehenen Patienten wurden bei der Berechn

\begin{tabular}{|c|c|c|c|c|c|c|c|c|c|c|c|c|c|c|c|c|c|c|c|}
\hline \multirow{3}{*}{ Name } & \multirow{3}{*}{$\begin{array}{c}\text { Ge- } \\
\text { wicht, } \\
\text { GröBe }\end{array}$} & \multirow{2}{*}{\multicolumn{5}{|c|}{ "xisod-Speicherung in \% Dosis }} & \multirow{3}{*}{$\begin{array}{c}\text { Gesamt- } \\
\text { 1.j1Jod im } \\
\text { Serum nach } \\
48 \text { std } \\
\% \text { Dosis/1 }\end{array}$} & \multirow{3}{*}{$\begin{array}{l}\text { Thyreo- } \\
\text { tropin" } \\
\text { test }\end{array}$} & \multirow{3}{*}{ Szintigramm } & \multirow{3}{*}{ Struma } & \multirow{3}{*}{$\begin{array}{l}P B^{12} I \\
\mu g-\% \\
\end{array}$} & \multicolumn{6}{|c|}{ L-Trijodthyronin-131 Jod } & \multirow{3}{*}{\begin{tabular}{|l} 
Gesamt- \\
Choleste- \\
rin im \\
Serum \\
mg- \% \\
\end{tabular}} & \multirow{3}{*}{ Bemerkungen } \\
\hline & & & & & & & & & & & & \multicolumn{2}{|c|}{ als tracer } & \multicolumn{2}{|c|}{ in $0,1 \mu \mathrm{g} / \mathrm{ml}$} & \multicolumn{2}{|c|}{ in $0,5 \mathrm{\mu g} / \mathrm{ml}$} & & \\
\hline & & 2 std & $6 \mathrm{Std}$ & $24 \mathrm{Std}$ & 48 std & $96 \mathrm{std}$ & & & & & & $\%$ geb. & $\%$ frei & \% geb. & $\%$ frei & $\%$ geb. & $\%$ frel & & \\
\hline $\begin{array}{c}\text { Wa. G., } \\
10,0\end{array}$ & $\overline{130}$ & 10 & 14 & 28 & 19 & - & - & neg. & $\begin{array}{l}\text { epiclav. Knoten ohne } \\
\text { Speicherung }\end{array}$ & $\begin{array}{l}\text { Struma } \\
\text { nodosa }\end{array}$ & 2,6 & $\begin{array}{l}88,5 \\
90,3\end{array}$ & 15,8 & 82,9 & $\underline{14,1}$ & $\begin{array}{l}93,0 \\
87,4\end{array}$ & 二 & 325 & primäres Myxödem \\
\hline $\begin{array}{c}\text { Ko. A., } \\
62,+9\end{array}$ & $\begin{array}{r}52 \\
154\end{array}$ & - & 8,7 & 17 & 13 & - & - & - & $\begin{array}{l}\text { re. epiclav. Tmp.-Feld } \\
\text { unterhalb Op.-Narbe }\end{array}$ & - & 3,1 & $\stackrel{86,5}{-}$ & $\stackrel{14,4}{-}$ & 85,8 & $\underline{15,4}$ & 76,5 & 17,4 & 344 & $\begin{array}{l}\text { vor } 9 \text { Jahren Strumaresek- } \\
\text { tion, Cholelithiasis, Dys- } \\
\text { proteinämie, BKS 19/45 }\end{array}$ \\
\hline $\begin{array}{c}\text { Ka. D., } \\
42,{ }^{\circ}\end{array}$ & 二 & - & 15 & 25 & 20 & - & 0,78 & - & $\begin{array}{l}\text { li. } 3 \text { cm gr. dichtes Imp.- } \\
\text { Feld, re. kaum Imp. }\end{array}$ & - & 0,8 & $\begin{array}{l}85,0 \\
86,1\end{array}$ & $\begin{array}{l}13,5 \\
12,1\end{array}$ & $\begin{array}{l}83,8 \\
84,7\end{array}$ & $\begin{array}{l}15,7 \\
1,5,2\end{array}$ & $\underline{77,2}$ & $\begin{array}{l}21,2 \\
22,1\end{array}$ & 280 & Zustand nach Strumitis \\
\hline $\begin{array}{l}\text { Gr. C., } \\
60, \frac{9}{+}\end{array}$ & $\begin{array}{r}58 \\
162\end{array}$ & - & 11 & 21 & 22 & - & - & - & schütteres Imp.-Muster & - & 2,0 & $\begin{array}{l}88,1 \\
87,3\end{array}$ & $\begin{array}{r}8,5 \\
10,7\end{array}$ & $\begin{array}{l}86,5 \\
84,9\end{array}$ & $\begin{array}{l}10,4 \\
11,7\end{array}$ & $\begin{array}{l}76,8 \\
78,8\end{array}$ & $\begin{array}{l}18,2 \\
18,7\end{array}$ & 356 & $\begin{array}{l}\text { Zust. n. }{ }^{131} \text { Jod-Th. u. sub- } \\
\text { tot. Resektion der } \\
\text { Schilddrüse }\end{array}$ \\
\hline $\begin{array}{l}\text { Kö. T., } \\
29, q\end{array}$ & $\begin{array}{r}62 \\
166\end{array}$ & - & 6,1 & 2,7 & - & - & 0,3 & 一 & $\begin{array}{l}\text { Imp.-Vermehrung im } \\
\text { Op.-Geb., lob. pyram. } \\
\text { angedeutet }\end{array}$ & - & 1,2 & $\overline{92,2}$ & $\begin{array}{l}8,7 \\
8,6\end{array}$ & - & 二 & $\begin{array}{l}89,3 \\
82,3\end{array}$ & $\begin{array}{l}12,4 \\
13,6\end{array}$ & 262 & $\begin{array}{l}\text { 131Jod-Th. u. Op. } 1963 \text { bei } \\
\text { malig.Papillom d.Schild- } \\
\text { drüse BKS 16/43, Sub- } \\
\text { stitution } 50 \mu \mathrm{g} \text { Thybon/ } \\
\text { die }\end{array}$ \\
\hline $\begin{array}{c}\text { Wa. B., } \\
51,9\end{array}$ & $\begin{array}{r}64 \\
155\end{array}$ & - & 2,8 & 4,8 & 5,1 & 一 & - & - & $\begin{array}{l}\text { Ganzkörper: im Hals- } \\
\text { bereich vermehrt Imp. }\end{array}$ & - & 3,0 & 91,5 & $\underline{8,1}$ & $\begin{array}{c}89,6 \\
-\end{array}$ & $\underline{8,7}$ & $\stackrel{87,5}{-}$ & 11,9 & 262 & - \\
\hline $\begin{array}{l}\text { Hö. A., } \\
40, \text { 古 }\end{array}$ & $\begin{array}{r}93 \\
165\end{array}$ & 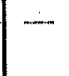 & 9,3 & 16 & 16 & - & 0,2 & - & $\begin{array}{l}\text { re. supraclav. mark- } \\
\text { stückgr. Imp.-Feld }\end{array}$ & - & 1,2 & $\stackrel{92,5}{\longrightarrow}$ & 11,4 & $\stackrel{84,4}{-}$ & $\underline{12,8}$ & $\stackrel{87,2}{-}$ & $\stackrel{13,0}{-}$ & 293 & $\begin{array}{l}\text { Myxödem nach Struma- } \\
\text { resektion } 1948\end{array}$ \\
\hline $\begin{array}{c}\text { Me. K., } \\
52, . q\end{array}$ & $\begin{array}{r}49 \\
162\end{array}$ & $一$ & 1,3 & 6,4 & 6,4 & - & 0,35 & 一 & $\begin{array}{c}\text { 1i. + re. kaum Imp. lob. } \\
\text { pyram. angedeutet }\end{array}$ & - & & $\stackrel{87,9}{-}$ & $\frac{10,5}{-}$ & $\underline{90,2}$ & $\stackrel{9,6}{-}$ & $\stackrel{84,5}{-}$ & $\underline{13,1}$ & - & $\begin{array}{l}\text { Myxödem nach Struma- } \\
\text { resektion }\end{array}$ \\
\hline $\begin{array}{c}\text { Hu. M., } \\
\text { q }\end{array}$ & - & & & ht gem & nacht & & - & - & - & - & 0,6 & $\stackrel{90,4}{-}$ & $\stackrel{8,3}{-}$ & - & - & $\stackrel{80,3}{-}$ & $\stackrel{20,6}{-}$ & - & ambulante Patientin \\
\hline $\begin{array}{l}\operatorname{Er} . \mathrm{K} . \\
32,0^{x}\end{array}$ & $\begin{array}{r}67 \\
170\end{array}$ & - & 38 & 53 & 55 & 45 & - & - & $\begin{array}{l}\text { unauff. homog. sym. } \\
\text { Imp..Bild }\end{array}$ & - & 3,6 & $\stackrel{88,0}{-}$ & 11,8 & 88,4 & $\underline{11,4}$ & $\stackrel{79,5}{-}$ & 16,5 & - & $\begin{array}{l}\text { Craniopharyngeom mit } \\
\text { sek. Hypogonadismus, } \\
\text { NNR-Insuffizienz }\end{array}$ \\
\hline $\begin{array}{l}\text { Utb. C., } \\
40, \text { o }\end{array}$ & $\begin{array}{r}70 \\
165\end{array}$ & - & 4,1 & 9,3 & 12 & - & - & - & $\begin{array}{l}\text { unauff. Imp.-Bild einer } \\
\text { gr. Schilddr. }\end{array}$ & $\begin{array}{l}\text { Struma } \\
\text { diffusa }\end{array}$ & $\begin{array}{l}\text { über } \\
20\end{array}$ & $\stackrel{88,6}{-}$ & 10,8 & $\stackrel{88,6}{-}$ & 10,6 & $\stackrel{86,2}{-}$ & $\stackrel{15,1}{-}$ & 353 & $\begin{array}{l}\text { vor } 5 \text { Tagen Cholecysto- } \\
\text { graphie }\end{array}$ \\
\hline $\begin{array}{c}\text { Sch. A., } \\
56, \approx\end{array}$ & $\begin{array}{r}67 \\
165\end{array}$ & 17 & 28 & 46 & 54 & - & - & - & - & - & 1,0 & $\begin{array}{r}87,7 \\
-\end{array}$ & 11,6 & $\stackrel{86,2}{-}$ & $\underline{11,8}$ & $\stackrel{84,8}{-}$ & $\underline{16,2}$ & 196 & $\begin{array}{l}\text { Strumaresektion } 1925, \\
0,1 \mathrm{mg} / \text { die Thyreoidin } \\
\text { seit } 1948\end{array}$ \\
\hline $\begin{array}{l}{[\mathrm{Wa} . \mathrm{H} .} \\
\left.14, \hat{o}^{\prime}\right]\end{array}$ & $\begin{array}{l}50 \\
160\end{array}$ & 85 & 94 & 89 & - & $一$ & - & 一 & $\begin{array}{l}\text { ausgedehnte Struma mit } \\
\text { homog. Imp.-Muster }\end{array}$ & $\begin{array}{l}\text { Struma } \\
\text { juven. } \\
\text { partim } \\
\text { nodosa }\end{array}$ & 2,2 & $\stackrel{87,8}{-}$ & 13,7 & 91,4 & $\underline{11,6}$ & $\stackrel{81,6}{-}$ & 19,3 & 174 & $\begin{array}{l}\text { Jodfehlverwertung ?, nach } \\
24 \text { Std Trenat }(1200 \mathrm{mg}) \text { : } \\
\text { kaum Kurvenkniok im } \\
\text { Radiojodtest }\end{array}$ \\
\hline $\begin{array}{l}\text { Pe. L., } \\
57, \%\end{array}$ & $\begin{array}{r}76 \\
160\end{array}$ & - & 30 & 49 & 52 & - & - & - & $\begin{array}{l}\text { linksseitiges hühnereigr. } \\
\text { Strumarezidiv }\end{array}$ & $\begin{array}{c}\text { Struma } \\
\text { nodosa }\end{array}$ & 2,8 & $\stackrel{89,9}{-}$ & $\frac{9,8}{-}$ & $\stackrel{87,0}{-}$ & $\stackrel{9,8}{-}$ & $\stackrel{91,0}{-}$ & $\stackrel{10,7}{-}$ & 265 & $\begin{array}{l}\text { Strumaresektion 1935, } \\
\text { Exophthalmus }\end{array}$ \\
\hline$\underset{\delta}{\mathrm{Se} . \mathrm{R} .}$ & - & - & 5 & 3 & - & 一 & - & neg. & - & - & & 91,6 & $\stackrel{8,4}{-}$ & - & $=$ & $\stackrel{88,6}{-}$ & 10,6 & - & ambulanter Patient \\
\hline
\end{tabular}




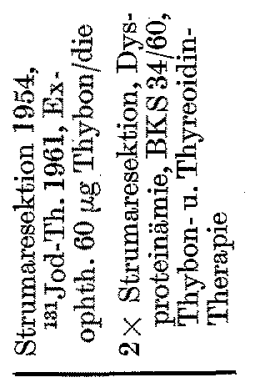

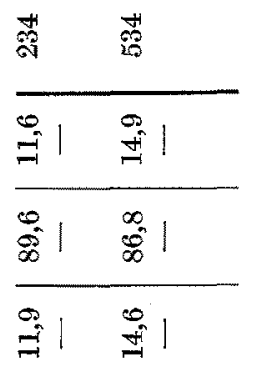

\begin{tabular}{|c|c|}
\hline$\stackrel{\infty}{\infty}$ & 11 \\
\hline $\begin{array}{l}\infty \\
0\end{array}$ & $\stackrel{-1}{ \pm 1}$ \\
\hline$\frac{\sigma}{\sigma} \mid$ & $\left|\frac{\infty}{\infty}\right|$ \\
\hline बi & बi \\
\hline 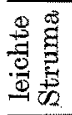 & 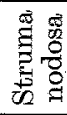 \\
\hline
\end{tabular}
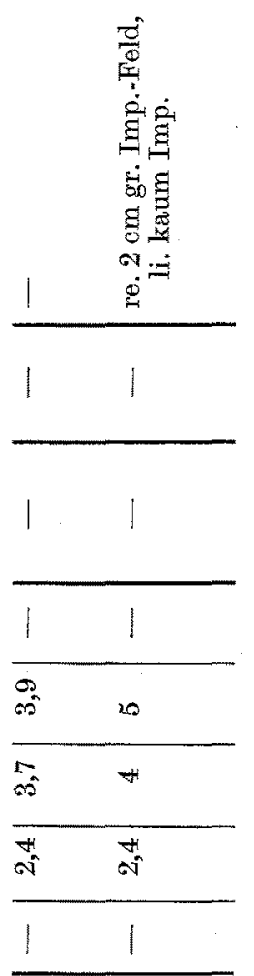

온 198

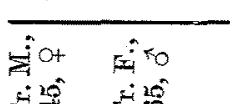

究 rechnen, wie das z. B. die durchschnittlich beschleunigte Jodraffung und höhere Jodaufnahme bei den Euthyreosen zeigt. Für die Diagnostik ist man daher auf weitere Verfahren, wie z. B. die Bestimmung des proteingebundenen Jods ( $\left.\mathrm{PB}^{127} \mathrm{I}\right)$ angewiesen. Abb. 6 zeigt, daß die Differenzen der Mittelwerte $(\bar{x})$ der PB $^{12}$ I-Werte der euthyreoten und hyperthyreoten sowie der hypothyreoten und euthyreoten Patientengruppen signifikant $(p<0,001)$ sind. Bei der Berechnung des Normalbereiches der Euthyreosen, welcher als Toleranzbereich ohne Vertrauenswahrscheinlichkeit $\left(\beta_{y}=\right.$ $0,95)$ angegeben wurde, zeigt sich, daß nur zwei PB $^{127}$ T-Werte von hyperthyreoten Patienten in diesen Normalbereich fallen. Hypothyreosen und Euthyreosen lassen sich dagegen aufgrund der PB ${ }^{127}$-Werte oft nicht differenzieren, wie das aus der Überlappung der PB ${ }^{127} \mathrm{~T}-W e r t e$ in Abb. $6 \mathrm{zu}$ ersehen ist.

In Abb. 7 wird das Verhältnis von sog. freiem zu proteingebundenem L-Trijodthyronin. ${ }^{131}$ Jod bei Hyperthyreosen, Euthyreosen und Hypothyreosen verglichen. Bei $\mathrm{Zu}$ satz kleinster Mengen $\mathrm{T}_{3}-13 \mathrm{I}$ als ,tracer" [12] sind die Mittelwertdifferenzen für sog. freies und proteingebundenes $\mathrm{T}_{3}-131$ bei Hyperthyreosen und Euthyreosen sowie bei Euthyreosen und Hypothyreosen signifikant $(p<0,001)$. Der Bereich der einfachen Standardabweichung der Hyperthyreosen ist von dem Normalbereich der Euthyreosen (Tabelle 2) deutlich getrennt. Nur die Werte eines Falles von kompensiertem "toxischen" Adenom mit einer fraglichen Hyperthyreose ( $\mathrm{Pa}$ tientin Zi. F., Tabelle 3) fielen in diesen Normalbereich. Dagegen lagen die Mittelwerte und 12 von 20 Werten des proteingebundenen sowie 11 von 20 Werten des sog. freien $\mathrm{T}_{3}-131$ bei hypothyreoten $\mathrm{Pa}$ tienten noch im Normalbereich der Euthyreosen (Abb. 7, linke Hälfte). Die sog. Verdrängungsversuche, bei denen dem Inkubationsgemisch nichtmarkiertes Trijodthyronin, wie auf der Abszisse angegeben, zugesetzt wurde, führten zu einer besseren Differenzierung von Euthyreose und Hypothyreose. Das zugesetzte, nicht markierte $\mathrm{T}_{3}$-127 verdrängt bei Hypothyreosen weniger proteingebundenes $\mathrm{T}_{3}$-131 als bei Euthyreosen (Abb. 7, rechte Hälfte). Die Mittelwerte und 12 von 20 Werten für proteingebundenes sowie

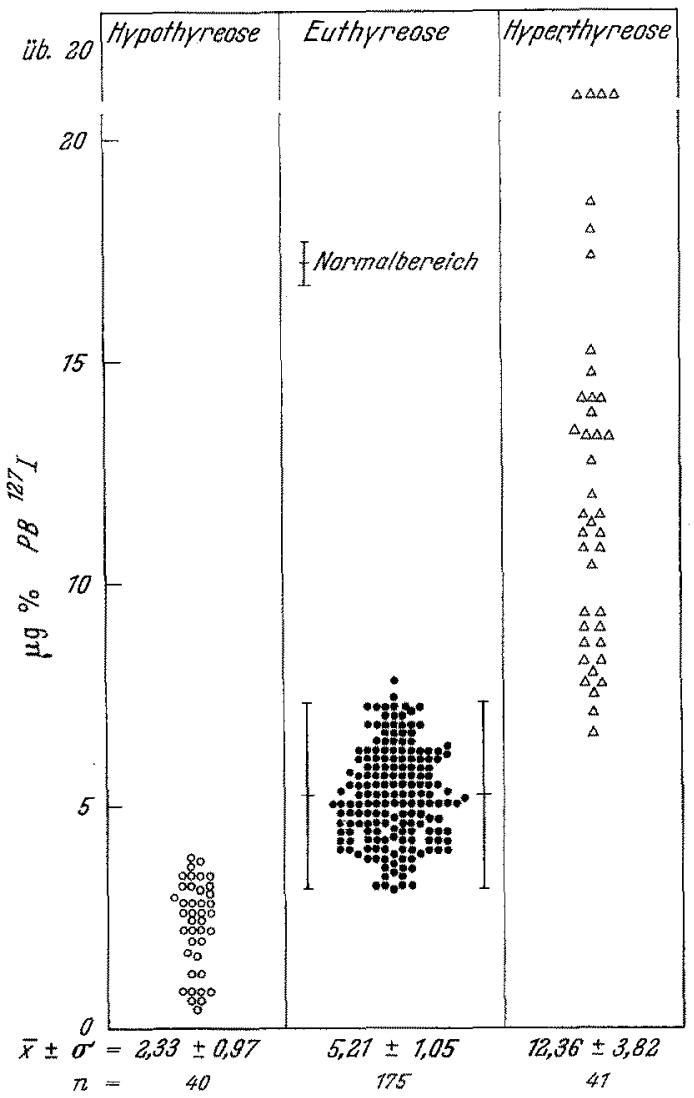

Abb. 6. Verteilung von Einzelwerten des proteingebundenen Jods ( $\left.\mathrm{PB}^{12} 1\right)$ bei Hypothyreosen, Eathyreosen und Fypertbyreosen im Vergleich zum Normalbereich der Euthyreosen. Die Mittelwerte mit der Standardabweichung $(\tilde{c}+\sigma)$ für Hypothyreosen und Hyperthyreosen wurden errechnet, obwohl es sich bei diesen beiden Kollektiven nicht um normal verteilte Kollektive handelt

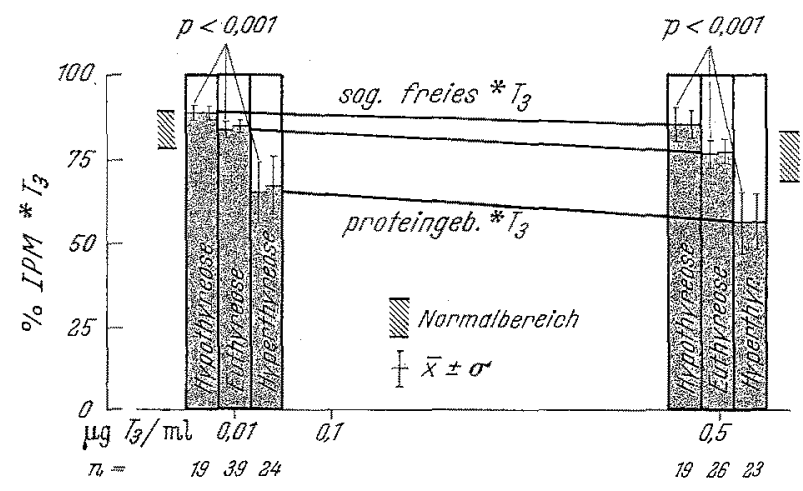

Abb. 7. Einfluß von nichtmarkiertem Trijodthyronin (Abszisse) auf da Verhältnis von sog. freiem za proteingebundenem $T_{s}-131$ im Serum von hypothyreoten, euthyreoten und hyperthyreoten Patienten. Dargestell sind Mittelwerte mit der standardabweichung $(\bar{x} \pm \sigma)$ von 17 hypothyreoten, 27 euthyreoten und 15 hyperthyreoten Patienten, links in jeder säule für den proteingebundenen, reehts für den sog. freien Anteil an $T_{3}-131$. Die Signin̈kanz der Differenzen der Mittelwerte für die Vergleichspaare Hypothyreose-Euthyreose und Euthyreose-Hyperthyreose und der Normalbereich dex Euthyreosen wurden nach $[49]$ berechnet. Die Werte für,$n^{\text {s* }}$ ergaben sich ans Mehrfachbestimmungen gleicher Seren

Tabelle 6. Mittelwerte und Standardabweichung $(\bar{x} \pm \sigma)$ für sog. freies und proteingebundenes L-Trijodthyronin-131 Jod bei Bypothyreosen

\begin{tabular}{|c|c|c|c|}
\hline & \multicolumn{3}{|c|}{ Trijodthyronin $(\mu \mathrm{g} / \mathrm{ml})$} \\
\hline & 0,01 & 0,1 & 0,5 \\
\hline $\begin{array}{l}\% \text { proteingebundenes } \\
\mathrm{T}_{3}-131\end{array}$ & $\begin{array}{r}88,82 \pm 2,3 \\
(n=19) \\
\end{array}$ & $\begin{array}{r}86,47 \pm 2,1 \\
(n=14) \\
\end{array}$ & $\begin{array}{r}84,58 \pm 5,0 \\
(n=19) \\
\end{array}$ \\
\hline$\%$ sog. freies $\mathbf{T}_{3}-131$ & $\begin{array}{r}10,88 \pm 2,2 \\
(n=19)\end{array}$ & $\begin{array}{r}10,93 \pm 2,2 \\
(n=15)\end{array}$ & $\begin{array}{r}15,43 \pm 3,3 \\
(n=18)\end{array}$ \\
\hline
\end{tabular}


12 von 21 Werten für sog. freies $\mathrm{T}_{3}-131$ der hypothyreoten Patienten (Tabelle 5) lagen jetzt außerhalb des Normalbereiches der Euthyreosen.

Die Methode der Dextran-Gel-Filtration miBt nicht den physiologischerweise proteingebundenen und freien Anteil des L-Trijodthyronins. Vielmehr verteilt sich das reversibel gebundene L-Trijodthyronin kompetitiv zwischen Serumproteinen und Dextran-Gel [12]. Auf Säulen mit größerem Gel-Bettvolumen, z. B. mit 5, $1 \mathrm{~g}$ statt $1,8 \mathrm{~g}$ Sephadex $\mathrm{G} 25$, fine, verschiebt sich das Verhältnis von sog. freiem zu proteingebundenem $\mathrm{T}_{3}-131$ zugunsten des freien Anteils (Tabelle 7). Diese Tatsache ließ sich ebenfalls zur Verbesserung der

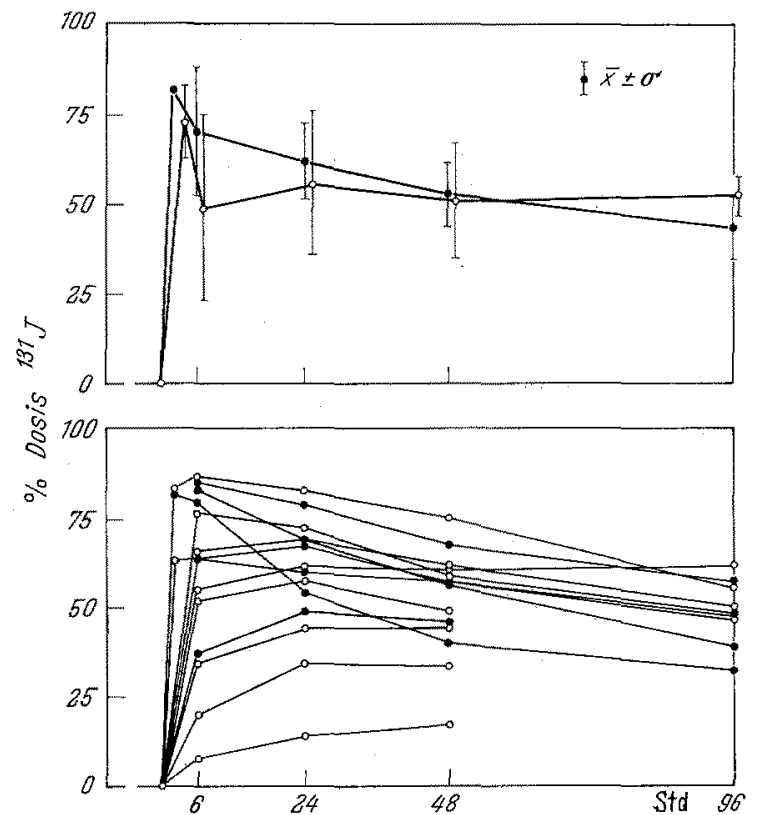

Abb. 8. Einzelwerte (unten) und Mittelwerte mit Standardabweichung $(\bar{x} \pm \sigma$, oben), der Radiojodspeicherung bei ehemaligen Hyperthyreosen $(-\bullet)$ und behandelten Strumen $(0-0)$

Differenzierung zwischen Euthyreosen und Hypothyreosen heranziehen. Es zeigte sich nämlich, daß bei Verwendung größerer Sephadex-Mengen den Serumproteinen hypothyreoter Patienten weniger $\mathrm{T}_{3^{-}}$13I entzogen wurde, als denen der euthyreoten Patienten.

Der Vergleich der hier untersuchten Verfahren der klinischen Schilddrüsenfunktionsdiagnostik zeigt, daß die Bestimmung des Verhältnisses von sog. freiem zu proteingebundenem $\mathrm{T}_{3}-131$ im Serum die bisherigen Methoden der Diagnostik, Radiojodspeicherungstest und proteingebundenes Jod, nicht unbedingt an Trenn. schärfe übertrifft. Einen Gewinn stellen diese Untersuchungen jedoch dar, wenn komplizierende Faktoren die übliche Diagnostik erschweren.

5. Operativ oder mit ${ }^{131}$ Jod verkleinerte Schilddrüsen. Eine erste Gruppe von Patienten, bei denen die übliche Schilddrüsendiagnostik erschwerende Faktoren vorliegen, ist in Tabelle 8 angeführt. Fs handelt sich um Patienten, die wegen einer Hyperthyreose oder einer Struma operativ oder mit Radiojod behandelt wurden. Bei vier der fünf Patienten, die ehemals eine Schild. drüsenüberfunktion hatten, erkennt man einen deutlich beschleunigten ${ }^{131}$ Jodumsatz, wie aus dem Abfall der Speicherungskurven und dem erhöhten Gesamt${ }^{131}$ Jod im Serum nach 48 Std (zwischen 1,6 und $4,5 \%$ Dosis je Liter) ersichtlich ist (Tabelle $8, \mathrm{Abb} .8$ ). Auch
Tabelle 7. Einfluß der Dextran-Gel-Menge auf das Verhältnis von sog. freiem zu proteingebundenem L-Trijodthyronin-131 Jod. de 6 Seren von euthyreoten und hypothyreoten Patienten wurden wie übich mit $T_{3}-131$ inkubiert. Die Dextran-Gel-Filtration er folgte dann einmal auf kleineren Säulen, die 1,8g Sephadex G-25, fine, enthielten $(h=18,0 \mathrm{~cm} ; d=0,8 \mathrm{~cm})$. Zum zweiten wurden aliquote Mengen weiterer Inkubationsansätze auf großen Säulen mit $5,1 \mathrm{~g}$ Sephadex $6-25$, fine, chromatographiert $(h=22,5 \mathrm{~cm}$; $d=1,2 \mathrm{~cm}$ ). Angegeben sind die gefundenen Einzelwerte sowie die Mittelwerte mit der Standardabweichung $(\tilde{x} \pm \sigma)$

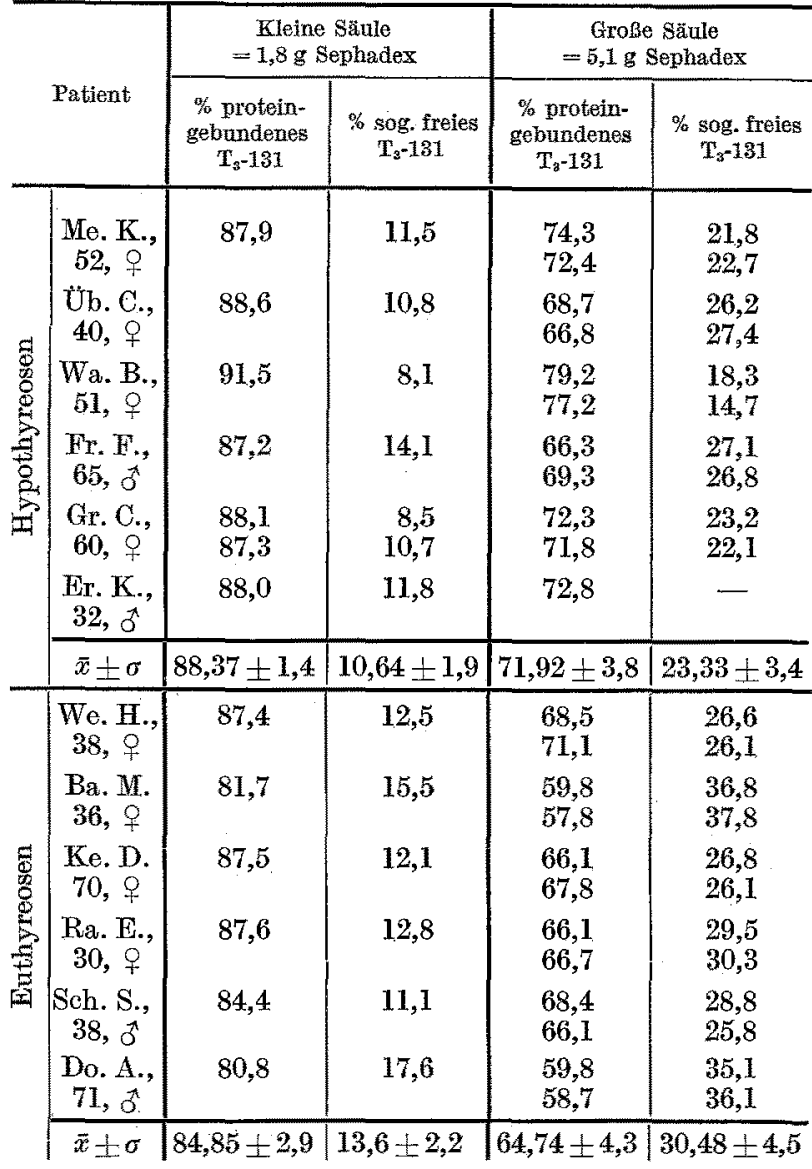

sechs von zehn Fällen mit behandelter Struma zeigten einen beschleunigten ${ }^{131}$ Jodumsatz, mit einem Gesamt_131Jod im Serum nach 48 Std zwischen 1,5 und $5,5 \%$ Dosis je Liter. Es ist verständlich, daß die Beurteilung dieser Fälle sich nicht ausschließlich auf den ${ }^{131}$ Jodspeicherungstest stützen darf. Hier liegt ein kompensatorisch beschleunigter Radiojodumsatz in dem durch Resektion verkleinerten Hormonjodpool vor. Die Diagnose des Schilddrüsenfunktionszustandes kann hier nur mit ergänzenden Methoden, wie mit Hilfe der Bestimmung des proteingebundenen Jods und der $\mathrm{T}_{3}$-131-Bindung an Serumproteine gestellt werden (Tabelle 9). Die Werte für proteingebundenes Jod ( $\left.\mathrm{PB}^{12 r} \mathrm{I}\right)$ lagen bei den ehemaligen Hyperthyreosen nach der Behandlung zwischen 3,0 und $7,0 \mu \mathrm{g}-\%$ und bei den Patienten mit behandelter Struma zwischen 3,2 und $5,8 \mu g-\%$. Die Mittelwerte $(\bar{x} \pm \sigma)$ des proteingebundenen und des sog. freien $\mathrm{T}_{3}-131$ lagen im Normalbereich der Euthyreosen (Tabelle 2, 9).

6. Endokriner Exophthalmus. Komplizierende Verhältnisse für die übliche Schilddrüsenfunktionsdiagnostik bestehen ferner bei Patienten mit endokrinem Exophthalmus, die sowohl bei Euthyreose als auch bei Hyperthyreose meistens eine steile Jodraffung mit einem beschleunigten Jodumsatz zeigten (Abb. 9, 10). 
Tabelle 8. Einzelwerte der Radiojodspeicherung, des proteingebundenen Jods und des sog. freien und proteingebundenen L-Trijodthyronin-131 Jods bei ehemaligen Hyperthyreosen und behandelten Strumen. Dargestellt sind die Einzelwerte der genannten Bestimmungen von 5 frïher hyperthyreoten Patienten, die jetzt als euthyreot anzusehen waren, und von 10 Patienten mit operativ oder durch 131Jod verkleinerten Strumen. Die routinemäßig untersuchte BKS und Serumelektrophorese sowie das Serumgesamteiweiß .

\begin{tabular}{|c|c|c|c|c|c|c|c|c|c|c|c|c|c|c|c|c|c|}
\hline \multirow{3}{*}{ Name } & \multirow{3}{*}{$\begin{array}{l}\text { Ge- } \\
\text { wicht, } \\
\text { Gröbe }\end{array}$} & \multirow{2}{*}{\multicolumn{5}{|c|}{${ }^{191}$ Jod-Speicherung in \% Dosis }} & \multirow{3}{*}{$\begin{array}{c}\text { Gesami- } \\
\text { 1s1Jod im } \\
\text { Sserum nach } \\
48 \text { Std } \\
\% \text { Dosis/1 }\end{array}$} & \multirow{3}{*}{ Szintigramm } & \multirow{3}{*}{ Struma } & \multirow{3}{*}{$\begin{array}{l}\mathrm{PB}^{12 x} \mathrm{I} \\
\mu \mathrm{g} \% \%\end{array}$} & \multicolumn{6}{|c|}{ L-Trijodthyronin-182Jod } & \multirow{3}{*}{ Bemerkungen } \\
\hline & & & & & & & & & & & \multicolumn{2}{|c|}{ als tracer } & \multicolumn{2}{|c|}{ in $0,1 \mu \mathrm{g} / \mathrm{ml}$} & \multicolumn{2}{|c|}{ in $0,5 \mu \mathrm{g} / \mathrm{ml}$} & \\
\hline & & $2 \mathrm{std}$ & $6 \mathrm{Std}$ & $24 \mathrm{Std}$ & $48 \mathrm{sid}$ & $96 \mathrm{std}$ & & & & & $\%$ geb. & $\%$ frei & $\%$ geb. & $\%$ frei & $\%$ geb. & $\%$ frei & \\
\hline
\end{tabular}

Ehemalige Hyperthyreosen - jetzt Euthyreosen

\begin{tabular}{|c|c|c|c|c|c|c|}
\hline $\begin{array}{c}\text { Bö. E., } \\
40, \stackrel{q}{q}\end{array}$ & $\begin{array}{r}87 \\
172\end{array}$ & - & 85 & 79 & 67 & 57 \\
\hline $\begin{array}{c}\text { Ka. B., } \\
64, \text { ? }\end{array}$ & $\begin{array}{r}52 \\
153\end{array}$ & 82 & 79 & 54 & 40 & 32 \\
\hline $\begin{array}{l}\text { We. E., } \\
56, \frac{9}{9}\end{array}$ & $\begin{array}{r}63 \\
162\end{array}$ & - & 64 & 60 & 57 & 48 \\
\hline $\begin{array}{c}\text { Ki. A., } \\
46, \text {, }\end{array}$ & $\begin{array}{r}63 \\
168\end{array}$ & - & 83 & 69 & 56 & 39 \\
\hline $\begin{array}{l}\text { Wü. G., } \\
52, \sigma^{*}\end{array}$ & 54 & - & 37 & 49 & 46 & - \\
\hline
\end{tabular}

\begin{tabular}{l|}
1,6 \\
4,5 \\
1,8 \\
2,7 \\
0,3
\end{tabular}

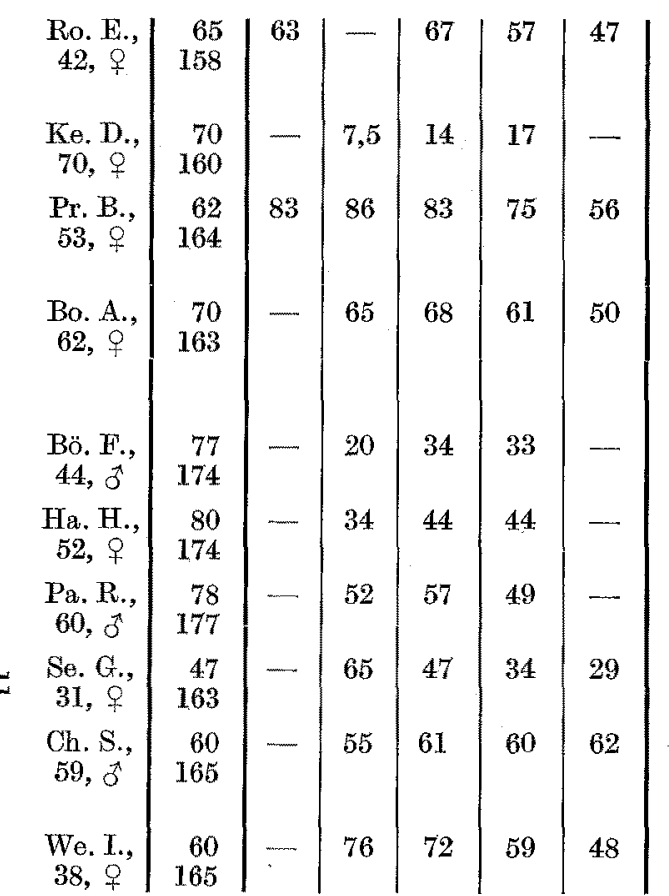

$$
\begin{array}{r}
2,3 \\
- \\
1,9 \\
1,5 \\
- \\
- \\
2,2 \\
5,5 \\
<0,3 \\
2,7
\end{array}
$$

$\mid$\begin{tabular}{l|l}
$\begin{array}{l}\text { homog. Imp.-Muster } \\
\text { re. gänseeigr., li. hühner- } \\
\text { eigr. Knoten }\end{array}$ & $\begin{array}{l}\text { weiche, pulsie } \\
\text { rende Stru } \\
\text { Struma nodo }\end{array}$ \\
- & \\
no. Imp.-Muster & \\
$\begin{array}{l}\text { re. kaum Imp., li. ver- } \\
\text { mehrt Imp. }\end{array}$ & -
\end{tabular}

Therapierte Strumen-jetzt

\begin{tabular}{|c|c|c|}
3,0 & 82,8 & 12,2 \\
6,2 & 80,0 & 16,4 \\
4,0 & - & - \\
& 86,3 & 14,2 \\
$(11,2)$ & 88,5 & - \\
7,0 & $\frac{11,5}{-}$ & - \\
& 88,0 & 10,0 \\
& & 10,2
\end{tabular}

\begin{tabular}{c|c}
85,6 & 13,6 \\
82,4 & 16,2 \\
- & - \\
$\frac{(71,5)}{-}$ & 12,9 \\
90,0 & 11,5 \\
- & - \\
88,1 & 11,1 \\
87,6 & 10,8 \\
&
\end{tabular}

\begin{tabular}{c|c|c} 
& $-81,5$ & - \\
& 71,3 & 38,2 \\
& - & \\
& 79,8 & - \\
1,5 & 82,5 \\
-1 & - \\
0,8 & $(84,5)$ &
\end{tabular}

\begin{tabular}{c|c}
$\frac{20,0}{-}$ & 13 \\
33,3 & $2 \times$ \\
20,2 & \\
17,9 & 1 \\
16,8 & \\
17,3 &
\end{tabular}

Jod-Th. vor 1 Monat, GU mehrmals über $+65 \%$

$2 \times{ }^{131}$ Jod-Th. vor 3 Monaten,

Hypophysenbestrahlung wegen

Exopthalmus, Hyperthyreose?

${ }^{131}$ Jod-Th. vor 9 Monaten

131 Jod-Th. vor 12 Monaten,

Euthyreose?

Strumaresektion 1950, ${ }^{181}$ Jod-Th. vor 4 Monaten, dekomp. tox. Adenom (TSH-Test), neg. Tri-
jodthyronin-Suppression

$1-$

-

homog., gr. Imp.-Muster

re. hühnereigr. dichtes Imp.-Feld, li. markstückgr. stummer Be

zirk

re. markstückgr. homog.

suprclav. Imp. .Feld

no. Imp.-Muster

no. Imp.-Muster

no. Imp.-Muster

beids. Strumarezidiv, li. Knoten, cranial $r \operatorname{Imp}$.

no. Imp.-Muster

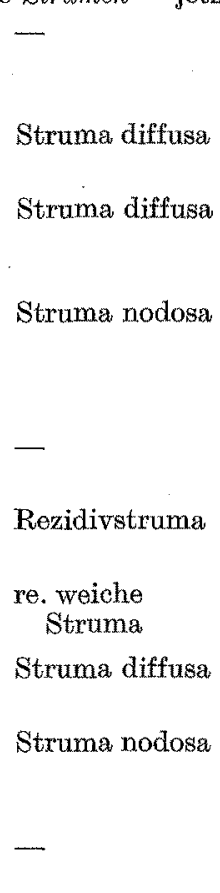

\begin{tabular}{|c|c|c|c|c|c|c|c|}
\hline$(10,2)$ & 85,0 & $\underline{13,8}$ & 87,5 & $\stackrel{15,3}{-}$ & $\underline{72,5}$ & $\stackrel{22,0}{-}$ & $\begin{array}{l}\text { 10,2-Wert unter Trijodthyronin, } \\
\text { Strumaresektion } 1948 \text {, seit, } 1 / 4 \text { Jahr } \\
\text { Perchlorat-Th., Exophthalmus }\end{array}$ \\
\hline 4,0 & 87,5 & $\underline{12,1}$ & 84,1 & 13,8 & 73,9 & $\underline{19,7}$ & $\begin{array}{l}\text { Strumareselktion } 1953,{ }^{131} \text { Jod-Th. } \\
\text { vor } 4 \text { Monaten }\end{array}$ \\
\hline 4,6 & - & 18,8 . & $\underline{79,3}$ & 18,5 & 71,0 & $\underline{30,0}$ & $\begin{array}{l}4 \times{ }^{131} \text { Jod-Th. 1964/65, maligner } \\
\text { Exophthalmus, neg. Trijod- } \\
\text { thyronin-Suppression }\end{array}$ \\
\hline 5,0 & $\begin{array}{l}86,6 \\
-\end{array}$ & $\underline{13,3}$ & 86,7 & 14,1 & $\stackrel{83,5}{-}$ & 18,1 & $\begin{array}{c}2 \times \text { Strumaresektion, jetzt } \\
\text { hühnereigroßes Rezidiv }\end{array}$ \\
\hline 4,8 & $\begin{array}{c}86,3 \\
(78,4)\end{array}$ & $\begin{array}{l}13,6 \\
13,5\end{array}$ & $\begin{array}{l}83,2 \\
84,5\end{array}$ & $\begin{array}{l}14,9 \\
15,3\end{array}$ & $\begin{array}{l}72,8 \\
75,2\end{array}$ & $\begin{array}{l}20,0 \\
18,4\end{array}$ & $\begin{array}{l}\text { Strumaresektion vor } 4 \text { Monaten } \\
\text { (Riedel-Struma) }\end{array}$ \\
\hline 5,8 & $\begin{array}{l}84,2 \\
83,8\end{array}$ & $\begin{array}{l}14,4 \\
15,4\end{array}$ & $\begin{array}{l}84,1 \\
83,8\end{array}$ & $\begin{array}{l}15,4 \\
15,4\end{array}$ & $\begin{array}{l}76,8 \\
75,6\end{array}$ & $\begin{array}{l}22,6 \\
23,3\end{array}$ & $2 \times$ Strumaresektion vor Jahren \\
\hline 3,2 & $\stackrel{80,6}{-}$ & 17,5 & $\stackrel{80,0}{-}$ & 18,7 & 71,2 & 31,8 & $\begin{array}{l}2 \times{ }^{131} \text { Jod-Th. vor } 8 \text { Monaten, } \\
\text { neg. Trijodthyronin-Suppress. }\end{array}$ \\
\hline $\begin{array}{l}3,6 \\
3,6\end{array}$ & $\stackrel{85,0}{-}$ & $\underline{14,1}$ & $\stackrel{85,7}{-}$ & $\underline{14,9}$ & 77,6 & $\underline{24,5}$ & 131Jod-Th. vor 6 Monaten \\
\hline 4,4 & $\stackrel{86,4}{-}$ & $\underline{12,8}$ & 二 & $\overline{-}$ & 78,8 & 19,7 & $\begin{array}{l}\text { Strumaresektion mit } 17 \text { Jahren, } \\
\text { Gesamtcholesterin } 386 \mathrm{mg}-\%\end{array}$ \\
\hline 5,6 & $\begin{array}{l}84,3 \\
82,8\end{array}$ & $\begin{array}{l}14,8 \\
15,0\end{array}$ & $\begin{array}{l}80,4 \\
80,5\end{array}$ & $\begin{array}{l}19,4 \\
17,3\end{array}$ & $\begin{array}{l}67,8 \\
69,1\end{array}$ & $\begin{array}{l}30,5 \\
27,9\end{array}$ & Strumaresektion 1955 \\
\hline
\end{tabular}


Auch das Gesamt-131 Jod im Serum nach 48 Std ist bei hyperthyreotem $(1,4-4,6 \%$ Dosis je Liter $)$ und euthyreotem $(0,3$ bis $5,5 \%$ Dosis je Liter) Exophthalmus praktisch immer erhöht. Da diese Patienten bei Einnahme von Trijodthyroxin im allgemeinen keine Suppression des Radiojodcyclus zeigen, also einen
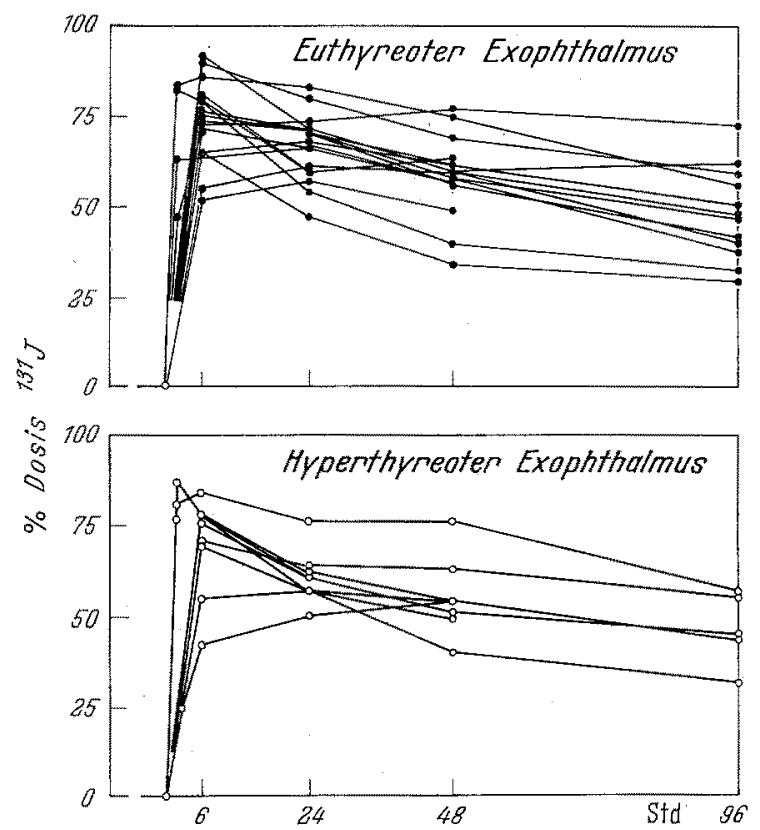

Abb. 9. Einzelwerte der Radiojodspeicherung bei euthyreotem (oben) und hyperthyreotem (unten) Exophthalmus. Es handelte sich um Eälle von gesichertem endokrinen Exophthalmus, die Diagnose des Schilddrüsenfunktionszustandes wurde unter Zugrundelegung der lzinischen Befunde und der Laborwerte (proteingebundenes ${ }^{22}$ Jod und $T_{8}-131$ Bindungsverhaltnisse) gestellt. Von den euthyreoten Fxophthalmen waren bel $10 \mathrm{~Pa}$ tienten entweder eine Struraaresektion, oder eine ein- oder mehrmalige

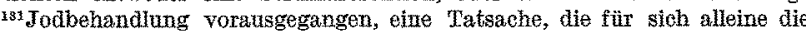
Beschleunigung des Radiojodcyclus erklären könnte

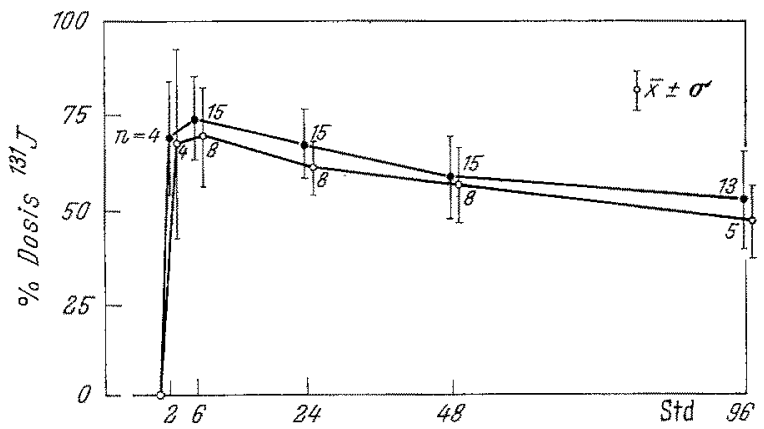

Abb. 10. Mittelwerte und Standardabweichung $(\bar{x}+\sigma)$ der Radiojodspeicherung bei euthyreotem $(-\bullet)$ und hyperthyreotem $(0-0)$ Exophthalmus

Tabelle 9. Mittelwerte und Standardabweichung $(\ddot{x}+\sigma)$ für proteingebundenes und sog. freies $L$-Trijodthyronin-131Jod bei ehemaligen Hyperthyreosen und behandelten Strumen

\begin{tabular}{|c|c|c|c|c|}
\hline & & \multicolumn{3}{|c|}{ Trijod thyronin $(\mu \mathrm{g} / \mathrm{ml})$} \\
\hline & & 0,01 & 0,1 & 0,5 \\
\hline \multirow{2}{*}{$\begin{array}{c}\text { Ehe- } \\
\text { malige } \\
\text { Hyper- } \\
\text { thyreosen }\end{array}$} & $\begin{array}{c}\% \text { protein- } \\
\text { gebundenes } \\
\mathrm{T}_{\mathbf{3}}-\mathbf{1 3 1}\end{array}$ & $\begin{array}{c}85,68 \pm 3,2 \\
(n=6)\end{array}$ & $\begin{array}{c}86,74 \pm 2,6 \\
(n=5)\end{array}$ & $\begin{array}{c}78,78 \pm 4,0 \\
(n=5)\end{array}$ \\
\hline & $\begin{array}{c}\% \text { sog. freies } \\
\mathrm{T}_{3}-131 \\
\end{array}$ & $\begin{array}{c}12,42 \pm 2,3 \\
(n=6)\end{array}$ & $\begin{array}{c}12,68 \pm 1,9 \\
(n=6)\end{array}$ & $\begin{array}{c}20,92 \pm 5,7 \\
(n=6)\end{array}$ \\
\hline \multirow{2}{*}{$\begin{array}{c}\text { Be* } \\
\text { handelte } \\
\text { Strumen }\end{array}$} & $\begin{array}{c}\% \text { protein- } \\
\text { gebundenes } \\
T_{3^{2}}-131\end{array}$ & $\begin{array}{c}84,77=1,9 \\
(n=11)\end{array}$ & $\begin{array}{c}83,32-2,6 \\
(n=12)\end{array}$ & $\begin{array}{c}74,29-4,6 \\
(n=13)\end{array}$ \\
\hline & $\begin{array}{c}\% \text { sog. freies } \\
\mathrm{T}_{3}-131\end{array}$ & $\begin{array}{c}14,55 \pm 1,8 \\
(n=13)\end{array}$ & $\begin{array}{c}16,08 \pm 1,8 \\
(n=12)\end{array}$ & $\begin{array}{c}23,73 \pm 4,7 \\
(n=13)\end{array}$ \\
\hline
\end{tabular}

Tabelle 10. Mittelwerte und Standardabweichung $(\bar{x}+\sigma)$ für proteingebundenes und sog. freies L-Trijodthyronin ${ }^{131} J o d$ bei Patienten mit endolorinem Exophthalmus. Angegeben sind die Mittelwerte der Bestimmungen bei 8 Patienten mit hyper. thyreotem endolvinen Exophthalmus und bei 16 Patienten mit euthyreotem endokriner Exophthatmis

\begin{tabular}{|c|c|c|c|c|}
\hline & & \multicolumn{3}{|c|}{ Trijodthyronin ( $\mu \mathrm{g} / \mathrm{mnl}$ ) } \\
\hline & & 0,01 & 0,1 & 0,5 \\
\hline \multirow{2}{*}{$\begin{array}{l}\text { Hyper- } \\
\text { thyreoter } \\
\text { Ex- } \\
\text { ophthal- } \\
\text { mus }\end{array}$} & $\begin{array}{c}\% \\
\text { protein- } \\
\text { gebun- } \\
\text { denes } \\
\mathrm{T}_{3}-131\end{array}$ & $\begin{array}{c}67,72+11,8 \\
(n=11)\end{array}$ & $\begin{array}{c}65,84 \pm 14,0 \\
(n=11)\end{array}$ & $\begin{array}{c}61,84 \pm 11,3 \\
(n=11)\end{array}$ \\
\hline & $\begin{array}{c}\% \text { sog. } \\
\text { freies } \\
\mathrm{T}_{\mathbf{3}^{-} \mathbf{1 3 1}}\end{array}$ & $\begin{array}{c}30,04 \pm 11,7 \\
(n=11)\end{array}$ & $\begin{array}{c}33,72 \pm 12,7 \\
(n=11)\end{array}$ & $\begin{array}{c}39,66 \pm 13,0 \\
(n=10)\end{array}$ \\
\hline \multirow{2}{*}{$\begin{array}{l}\text { Euthyre- } \\
\text { oter Ex: } \\
\text { ophthal- } \\
\text { mus }\end{array}$} & $\begin{array}{c}\% \\
\text { protein- } \\
\text { gebun- } \\
\text { denes } \\
\mathrm{T}_{3}-131 \\
\end{array}$ & $\begin{array}{r}83,9 \pm 2,1 \\
(m=16)\end{array}$ & $\begin{array}{c}82,93 \pm 2,7 \\
(n=17)\end{array}$ & $\begin{array}{c}74,26+4,5 \\
(n=19)\end{array}$ \\
\hline & $\begin{array}{l}\% \text { sog. } \\
\text { freies } \\
\mathrm{T}_{3}-131\end{array}$ & $\begin{array}{c}14,82 \pm 2,0 \\
(n=19)\end{array}$ & $\begin{array}{c}16,65 \pm 2,0 \\
(n=17)\end{array}$ & $\begin{array}{c}24,72 \pm 5,1 \\
(n=19)\end{array}$ \\
\hline
\end{tabular}

negativen Trijodthyronin-Suppressionstest aufweisen, wird man sich auch bei diesen Fällen für die Diagnose des Schilddrüsenfunktionszustandes auf Methoden, wie die Bestimmung des proteingebundenen Jods und des Verhältnisses von sog. freiem zu proteingebundenem $\mathrm{T}_{3}-131$, stützen müssen. Die $\mathrm{PB}^{127} \mathrm{I}-$ Werte lagen bei hyperthyreotem Exophthalmus zwischen 8,4 und $18,6 \mu \mathrm{g}-\%$ und bei euthyreotem Exophthalmus zwischen 2,4 und 7,2 $\mu \mathrm{g}-\%$. Tabelle 10 zeigt das Ergebnis der Bestimmung des sog. freien und des proteingebundenen Anteils an $\mathrm{T}_{3}-131$ bei Patienten mit endokrinem Exophthalmus. Die Mittelwertsdifferenzen von proteingebundenem und sog. freiem $\mathrm{T}_{3}-131$ bei euthyreotem und hyperthyreotem Exophthalmus sind signifikant $(\mathrm{p}<0,001)$. Dabei fielen 3 von 11 Werten für sog. freies $\mathrm{T}_{3}-131$ der Patienten mit hyperthyreotem Exophthalmus in den Normalbereich der Euthyreosen, während ein Wert für sog. freies $\mathrm{T}_{3^{-131}}$ eines euthyreoten Patienten mit endokrinem Exophthalmus außerhalb des Normalbereiches der Eathyreosen lag.

7. Einfluß von Jodgaben auf die Schilddrüsenfunktionsdiagnostik. Schwierigkeiten in der Schilddrüsenfunktionsdiagnostik treten auf, wenn Patienten Jod, z. B. in Form von jodhaltigen Röntgenkontrastmitteln, Medikamenten, Zahnpasta oder von Jodpinselungen erhalten. Man findet in diesen. Fällen häufig durch Jodgabe erhöhte $\mathrm{PB}^{127} \mathrm{I}$-Werte und $\mathrm{z}$. T. extrem nied rige ${ }^{131}$ Jodspeicherungskurven. 24 Patienten wurden z. T. vor und nach Applikation von Kontrastmitteln oder jodhaltigen Medikamenten einer Untersuchung mit den zur Verfügung stehenden Verfahren der Sehilddrüsenfunktionsdiagnostik unterzogen. Die Befunde von sieben repräsentativen Patienten sind in $A b b, 11$ zusammengefaßt. Es ist verständlich, daß der Radiojodspeicherungstest und die Bestimmung des proteingebundenen Jods nach Jodzufuhr für die Schilddrüsenfunktionsdiagnostik häufig nicht zu verwerten sind. Abb. 11 zeigt an einigen Beispielen den Anstieg des $\mathrm{PB}^{127} \mathrm{~T}$ nach Kontrastmittelgabe und die in einigen. Fällen nachweisbare, sog. exogene Speicherungsdepression im Radiojodspeicherungstest. Der sog. freie und der proteingebundene Anteil an $\mathrm{T}_{3}-131$ 
ist dagegen vor und nach Kontrastmittelgabe praktisch unverändert. In diesen Fällen ist die Bestimmung der Bindungsverhältnisse des $\mathrm{T}_{3}$-131 daher ein besonders wertvolles diagnostisches Hilfsmittel.

Der Anstieg des PB ${ }^{127}$ nach Kontrastmittelgabe war keineswegs bei allen Kontrastmitteln und allen Patienten große Struma, so daß klinisch der Verdacht auf das Vorliegen einer Hyperthyreose erweckt wurde. Die Laborbefunde zeigten u. a. eine deutliche Dys- und Hypoproteinämie und eine stark beschleunigte Blutkörperchensenkungsgeschwindigkeit. Das Serumcholesterin betrug $268 \mathrm{mg}$ \% $\%$. Beim Radiojodspeicherungstest wurden von der Patientin nur $0,6 \%$ der verabreichten Aktivität gespeichert. Das PB ${ }^{127} \mathrm{I}$ war mit über $20 \mu \mathrm{g} \%$ maxi-

\begin{tabular}{|c|c|c|c|c|c|c|c|c|c|c|}
\hline \multirow{3}{*}{ Name } & \multirow{3}{*}{$\begin{array}{c}\text { Gewicht } \\
\text { Grobe }\end{array}$} & \multirow{3}{*}{$\begin{array}{l}\text { Kontrast- } \\
\text { mitiel }\end{array}$} & \multirow{3}{*}{ wann } & \multirow{2}{*}{\multicolumn{2}{|c|}{$\mathrm{PB}^{12 \pi} \mathrm{I}(\mu \mathrm{g}-\%)$}} & \multirow{3}{*}{$\begin{array}{l}24 \text { Std } 131 \mathrm{~J}- \\
\text { Speicher } \\
\text { in \% Dosis }\end{array}$} & \multicolumn{4}{|c|}{ LmTrijodthyronin-131 J } \\
\hline & & & & & & & \multicolumn{2}{|c|}{$\%$ sog. freies } & \multicolumn{2}{|c|}{$\%$ proteingebundenes } \\
\hline & & & & $\begin{array}{l}\text { vorher } \\
\text { über }\end{array}$ & nacher & & $\begin{array}{l}\text { vorher } \\
28\end{array}$ & nacher & $\begin{array}{l}\text { vorher } \\
92\end{array}$ & nachor \\
\hline $\begin{array}{l}\text { Ul., } 56 \text { J., } \widehat{o} \text {, Nephrotisches } \\
\text { Syndrom, Euthyreose }\end{array}$ & $\begin{array}{r}75 \\
179\end{array}$ & $\begin{array}{c}\text { Urografin } \\
\qquad 76 \%\end{array}$ & 11 Tagen $=$ & $\begin{array}{l}=20 \\
-10 \\
-5\end{array}$ & & 70 & $\begin{array}{l}24 \\
16 \\
8 \\
\end{array}$ & & $\begin{array}{r}-84 \\
-76 \\
68 \\
\end{array}$ & \\
\hline $\begin{array}{l}\text { Ri., } 19 \text { J., } d, \text { Hypertonus, } \\
\text { Euthyreose }\end{array}$ & $\underline{84}$ & $\begin{array}{c}\text { Urografin } \\
76 \%\end{array}$ & $\begin{array}{l}\text { vor } \\
3 \text { Tagen }\end{array}$ & $\begin{array}{l}= \\
-10 \\
-54\end{array}$ & & 72 & $\begin{array}{l}-24 \\
-16 \\
8 \\
\end{array}$ & 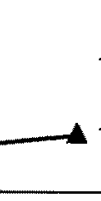 & $\begin{array}{r}-84 \\
76 \\
68\end{array}$ & \\
\hline $\begin{array}{l}\text { Wa., } 51 \text { J., }, \\
\text { Anämie, Hypothyreose }\end{array}$ & $\begin{array}{r}64 \\
155\end{array}$ & $\begin{array}{c}\text { Urografin } \\
\mathbf{7 6 \%}\end{array}$ & vor $=$ & $\begin{array}{l}-10 \\
-5\end{array}$ & & 4,8 & $\begin{array}{r}24 \\
-16 \\
8 \\
\end{array}$ & & $\begin{array}{r}84 \\
76 \\
68 \\
\end{array}$ & \\
\hline $\begin{array}{l}\text { Ho., } 41 \mathrm{~J}, \text {, } \\
\text { obliterans, Endangitis }\end{array}$ & $\begin{array}{r}85 \\
171\end{array}$ & $\begin{array}{l}\text { Urografin } \\
60 \%\end{array}$ & $\begin{array}{l}\text { vor } \\
10 \text { Tagen }\end{array}$ & 10 & & 61 & $\begin{array}{l}24 \\
16 \\
8 \\
8\end{array}$ & & $\begin{array}{r}84 \\
76 \\
68 \\
\end{array}$ & \\
\hline $\begin{array}{l}\text { Ko., } 62 \mathrm{~J}, \text {, }, \text { Dysprotein- } \\
\text { ämie, Hypothyreose, } \\
\mathrm{T}_{3} \text {-Therapie }\end{array}$ & $\begin{array}{r}52 \\
154\end{array}$ & Biligrafin & $\begin{array}{l}\text { vor } \\
3 \text { Tagen }\end{array}$ & $=$ & & 2,0 & $\begin{array}{r}-24 \\
-16 \\
8 \\
\end{array}$ & & $\begin{array}{r}84 \\
76 \\
68 \\
\end{array}$ & \\
\hline $\begin{array}{l}\text { Üb., } 40 \text { J., }, \text {, Verdacht auf } \\
\text { Cholelithiasis, Hypo- } \\
\text { thyreose }\end{array}$ & $\begin{array}{r}70 \\
165\end{array}$ & Biligrafin & $\begin{array}{l}\text { vor } \\
5 \text { Tagen }\end{array}$ & $=$ & & 9,3 & $\begin{array}{r}-24 \\
-16 \\
8 \\
\end{array}$ & & $\begin{array}{r}-84 \\
76 \\
68 \\
\end{array}$ & - \\
\hline $\begin{array}{l}\text { De., } 62 \text { J., }, \text {, Dysprotein- } \\
\text { ämie bei Lymphosarkom, } \\
\text { Hyperthyreose? }\end{array}$ & 59 & $\begin{array}{l}\text { Lipiodol } \\
10 \mathrm{ml}\end{array}$ & $\begin{array}{c}\text { vor } \\
3 \text { Wochen }\end{array}$ & $\begin{array}{l}= \\
-10\end{array}$ & & $\begin{array}{c}6 \text { Std } \\
0,6\end{array}$ & $\begin{array}{l}-24 \\
-16 \\
8\end{array}$ & & $\begin{array}{r}-84 \\
-76 \\
68\end{array}$ & $\begin{array}{l}x \\
\times\end{array}$ \\
\hline
\end{tabular}

Abb. 11. EinfluB von Röntgenkontrastmittein (Jodapplikation) auf das proteingebundene Jod ( $\mathrm{PB}^{132} \mathrm{~T}$ ), die Radiojodspetcherung und das Verhältnis von sog. freiem zu proteingebundenem $T_{3}-131$. Dargestellt sind die Werte von drei euthyreoten, drei hypothyreoten Patienten und einer fraglichen Hyperthyreose. In drei Trallen konnten die PB'12?I-Werte leider nur nach Jodgabe bestimmt werden. Die Radiojodspeicherungsteste wurden alle nach Kontrastmittelgabe durchgeführt, der zeitliche Abstand ist angegeben. Bei drei Patienten (Wa., Uob., De.) erfolgte die Bestimmung der $\mathrm{T}_{3}-131$ Bindungsverhältnisse nur nach Kontrastmittelgabe

gleich konstant nachzuweisen. Auch in der Literatur findet man Angaben über ein sehr unterschiedliches Verhalten, z. B. der ${ }^{131}$ Jodspeicherungsteste nach Gabe von anorganischem Jod $^{17}$. Die Gesetzmäßigkeiten der Beziehungen zwischen Jodapplikation und Veränderungen des proteingebundenen Jods und der Radiojodspeicherungsteste sind Gegenstand weiterer Untersuchungen. - Auch die Menge und das Verhältnis der Serumeiweißkörper beeinflußt die Bindung von $T_{-131}$ an Serumproteine. Wie schwierig aus diesen Gründen die Schilddrüsenfunktionsdiagnostik gelegentlich ist, soll durch folgende Beispiele erläutert werden. Bei der Patientin De. (Abb. 11) wurde wegen eines Lymphosarkoms des Oberschenkels eine Lymphoangiographie 3 Wochen vor unseren Untersuchungen durchgeführt. Die Patientin litt unter Tachyarrhythmien und einer Linksinsuffizienz des Herzens. Es bestand eine derbe mal erhöht. Bei der Bestimmung des Verhältnisses von sog. freiem $z u$ proteingebundenem $T_{3}-131$ fanden sich Prozentzahlen und ein Verdrängungseffekt, wie er bei Hyperthyreosen gefunden wurde. PB ${ }^{127} \mathrm{~T}$-Wert und ${ }^{131} \mathrm{Jodspeicherung} \mathrm{konnten}$ wegen der vorausgegangenen Röntgenkontrastuntersuchung nicht verwertet werden. Die $T_{3}-131$ Bindungsverhältnisse mußten bei der erheblichen Dys- und Hypoproteinämie ebenfalls angezweifelt werden. Eine sichere Diagnose des Schild drüsenfunktionszustandes war zu diesem Zeitpunkt also nicht möglich. - Die Patientin Ứb. (Abb. 11) klagte über cyclisch auftretende Ödeme. Die weitere Befragung erregte klinisch den Verdacht auf das Vorliegen einer Hypothyreose. Die kurz vor unserer ersten Untersuchung auswärts durchgeführte Cholecystographie hatte zu einer Verfälschung der PB ${ }^{127}$ TWerte und des ${ }^{131}$ Jodspeicherungstestes geführt. Das erhöhte 
Serumcholesterin $(353 \mathrm{mg}-\%$ ) und die auch im Verdrängungsversuch niedrigen Werte für sog. freies und hohen Werte für proteingebundenes $\mathrm{T}_{8}-131$ unterstützten die Annahme einer Hypothyreose. Die Patientin wurde unter einer Behandlung mit täglich $100 \mu \mathrm{g}$ L-Trijodthyronin (Thybon $\mathbb{B}$ ) beschwerdefrei.

8. Zur Bestimmung des Verhältnisses von sog. freiem zu proteingebundenem L-Thyroxin-131Jod. In Ergänzung der Bestimmung des Verhältnisses von sog. freiem zu proteingebundenem $\mathrm{T}_{3}-131$ untersuchten wir die Bindung von L-Thyroxin-131 Jod $\left(\mathrm{T}_{4}-131\right)$ an Serumproteine mit der Dextran-Gel-Filtrationsmethode. Inkubation, Dextran-Gel-Filtration und Verdrängungsversuche wurden in ganz analoger Weise wie bei der Bestimmung der $\mathbf{T}_{\mathrm{s}}-131$ Bindung an Serumproteine durchgeführt [12]. Die Befunde sind in Tabelle 11

Tabelle 11. Bestimmung des Verhältnisses von sog. Ireiem zu proteingebundenem L-Thyroxin-131Jod mittels Dextran-GelFiltration. Angegeben sind Einzelwerte und Mittelwerte mit der Standardabweichang $(\vec{x}+\sigma)$ von Seren 12 euthyreoter und 3 hyperthyreoter Patienter. Inkubation und Dextran-Gel-Fithration erfolgten in analoger Weise, wie für die Verdrängungs. versuche mit $T_{3}-131$ beschrieben $[12]$

\begin{tabular}{|c|c|c|c|c|c|c|c|}
\hline & \multirow{3}{*}{ Name } & \multicolumn{6}{|c|}{ L-Thyroxin-131 Jod } \\
\hline & & \multicolumn{2}{|c|}{ als tracer } & \multicolumn{2}{|c|}{ In $0,17 \mu \mathrm{g} / \mathrm{ml}$} & \multicolumn{2}{|c|}{ in $0,5,1 \mathrm{~g} / \mathrm{ml}$} \\
\hline & & $\%$ geb. & $\%$ frei & $\%$ geb. & $\%$ frei & $\%$ eb. & $\%$ frei \\
\hline \multirow[t]{2}{*}{ 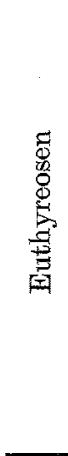 } & 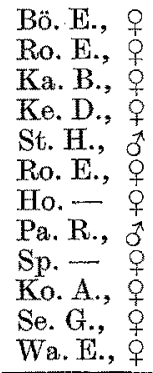 & $\begin{array}{c}97,2 \\
97,2 \\
95,8 \\
95,8 \\
101,7 \\
99,2 \\
(82,4) \\
99,0 \\
99,9 \\
95,3 \\
98,6 \\
97,0\end{array}$ & $\begin{array}{l}2,0 \\
1,8 \\
3,2 \\
2,0 \\
1,8 \\
1,6 \\
1,2 \\
2,5 \\
1,9 \\
2,9 \\
1,3 \\
2,5\end{array}$ & $\begin{array}{l}96,5 \\
98,8 \\
97,9 \\
94,6 \\
98,2 \\
99,8 \\
95,8 \\
97,2 \\
97,6 \\
94,4 \\
98,7 \\
99,0\end{array}$ & $\begin{array}{l}1,7 \\
1,8 \\
2,6 \\
1,9 \\
1,5 \\
1,8 \\
1,4 \\
8,8 \\
8,6 \\
5,0 \\
1,5 \\
2,9\end{array}$ & $\begin{array}{l}94,0 \\
98,5 \\
92,2 \\
96,7 \\
95,4 \\
96,3 \\
95,2 \\
- \\
- \\
\overline{-} \\
96,3 \\
5,8\end{array}$ & $\begin{array}{l}1,9 \\
2,3 \\
6,6 \\
5,2 \\
1,7 \\
2,0 \\
2,2 \\
- \\
- \\
- \\
1,6 \\
2,9\end{array}$ \\
\hline & $\begin{array}{r}\bar{x} \\
\pm \sigma \\
\end{array}$ & $\begin{array}{r}96,6 \\
\pm 4,6 \\
\end{array}$ & $\begin{array}{l}2,1 \\
\pm 0,6 \\
\end{array}$ & $\begin{array}{r}97,4 \\
\pm 1,7 \\
\end{array}$ & $\begin{aligned} & 3,3 \\
& \pm 2,6 \\
&\end{aligned}$ & $\begin{array}{r}95,6 \\
\pm 1,7\end{array}$ & $\begin{array}{l}2,9 \\
\pm 0,2 \\
\end{array}$ \\
\hline \multirow{2}{*}{ 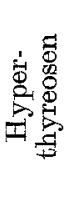 } & $\begin{array}{l}\text { Ri. H., } \\
\text { So. I., } \\
\text { Zi. F., } \\
\end{array}$ & $\begin{array}{l}96,4 \\
94,8 \\
99,8 \\
97,4\end{array}$ & $\begin{array}{l}5,8 \\
3,6 \\
3,6 \\
3,2 \\
\end{array}$ & $\frac{98,6}{103,5}$ & $\begin{array}{l}3,1 \\
3,0 \\
3,3 \\
-\end{array}$ & $\overline{93,3}$ & $\begin{array}{l}\overline{3,8} \\
- \\
-\end{array}$ \\
\hline & $\begin{array}{c}\bar{x} \\
\pm \sigma\end{array}$ & $\begin{array}{r}97,1 \\
\pm 1,8\end{array}$ & $\begin{array}{r}4,0 \\
\pm 1,0\end{array}$ & $\begin{array}{r}101,0 \\
\pm 2,6\end{array}$ & $\begin{array}{c}3,2 \\
\pm 0,1\end{array}$ & 93,3 & 3,8 \\
\hline
\end{tabular}

zusammengefaßt. Trotz der kleinen Zahl der untersuchten Patienten ist erkenntlich, daß nur ein geringfügiger Unterschied der Proteinbindung von $\mathrm{T}_{4}-131$ im Serum von euthyreoten und von hyperthyreoten Patienten besteht. Auch im Verdrängungsversuch fanden sich bei Euthyreosen und Hyperthyreosen Werte für sog. freies $T_{4}-131$, die fast noch im Bereich der Fehlerbreite der Methode lagen. Für die Schilddrüsenfunktionsdiagnostik ist diese Methode daher wenig vorteilhaft. Die Bedeutung der Befunde für die Anschauungen über die Pathogenese der Hyperthyreose wird in der Diskussion besprochen.

\section{Diskussion}

Über die Technik der Bestimmung der Bindung von L-Trijodthyronin-131 Jod an Serumproteine mittels Dextran-Gel-Filtration wurde von uns früher ausführlich berichtet [12]. Es sei noch einmal betont, daß bei diesem Verfahren nicht der physiologischerweise proteingebundene und freie Anteil des Hormons be- stimmt wird, sondern ein ,sog. freier" Anteil an $T_{3}-131$, der an Dextran-Gel gebunden wird. Überlegungen zur physiologischen Bedeutung des, ,freien“" bzw. ,sog, freien" Anteils an $\mathrm{T}_{3}-131$ hatten uns zu der Annahme geführt, daß diese eine physiologisch bedeutsame Rolle spielen [12]. - Die Werte für sog. freies L-Thyroxin-131.Jod lagen, auch bei Zusatz erheblicher Mengen nicht markierten Thyroxins in den sog. Verdrängungsversuchen, in einer GröBenordnung, die beinahe noch der Fehlerbreite der Methode entsprach.

Bei der Bestimmung des ,freien" Anteils an L-Thyroxin mit der Dialysetechnik [18] fand man allerdings, daß ein signifikanter Unterschied der Werte zwischen Hyperthyreose und Euthyreose sowie Euthyreose und Hypothyreose besteht. Die mitgeteilten Konzentrationen liegen im Bereich von Millimikrogramm/100 ml. Werte für ,freies" L-Trijodthyronin aus Dialyseversuchen sind uns für Hyperthyreosen aus der Literatur nicht bekanntgeworden. Bei hyperthyreoten Patienten ist der prozentuale „,sog. freie" Anteil des $\mathrm{T}_{3}-131$ z. T. ca. 20 fach böher als der ,,sog. freie" Anteil an $\mathrm{T}_{4}-131$. Diese Tatsache spricht zusammen mit der bekannten größeren hormonellen Wirksamkeit des L-Trijodthyronins trotz der kleineren. Gesamtkonzentration an L-Trijodthyronin im Blut dafür, daß die Vermehrung des nicht proteingebundenen Anteils an L-Trijodthyronin für die Pathogenese der Hyperthyreose ein wesentlicher Faktor ist. Ursache der Erhöhung des sog. freien Anteils an $T_{3}-131$ dürfte eine höhere Gesamtkonzentration an Thyroxin im Serum der hyperthyreoten Patienten sein, welche zu einer Verdrängung des proteingebundenen Anteils des $\mathrm{T}_{3}-131$ führt $[12,25]$.

Unterschiede in den Bindungsverhältnissen der Schilddrüsenhormone sind für die Klinik von Bedeutung. Es sind. Fälle von Schilddrüsenunterfunktion mit erhöhtem proteingebundenem Jod $\left(\mathrm{PB}^{127} \mathrm{I}\right)$, bei denen die Menge des thyroxinbindenden Globulins erhöht und die $\mathrm{T}_{3}$-131-Erythrocyten-Aufnahme er niedrigt war, beschrieben worden [19]. Ebenso gibt es Fälle von Hyperthyreosen mit normalen PB ${ }^{127} \mathrm{I}$-Werten, bei denen das thyroxinbindende Globulin (TBG) erniedrigt und die $\mathbf{T}_{3}$-131-Erythrocyten-Aufnahme erhöht war. Von VIGIER [16] fand bei 41 hyperthryreoten Patienten in drei Fallen PB ${ }^{127} \mathrm{I}-$ Werte unter $7,0 \mu \mathrm{g}-\%$. Bei 41 hyperthyreoten Patienten fanden wir zweimal PB $^{127}$ I-Werte, die im Normalbereich der Euthyreosen lagen. Möglicherweise kommen Hyperthyreosen mit bevorzugter Bildung von L-Trijodthyronin vor, welche dann keine erhöhten PB ${ }^{12 T}$ T haben müssen [20]. - DaB in der Schwangerschaft erhöhte PB $^{127}$ I-Werte bestehen können, ohne daß ein hyperthyreoter Funktionszustand vorliegt, ist auf die erhöhte. L-Thyroxinbindnng zurückzuführen [21]. - Postoperativ findet sich häufig eine Erhöhung des ,freien" T-Thyroxins von z. B. $3 \times 10^{-11}$ auf $6 \times 10^{-11}$ molar und eine Abnahme der Bindungskapazität des L-Thyroxin-bindenden Präalbumins [22] beikonstant bleibendem $\mathrm{PB}^{127} \mathrm{~T}$. Auch bei manchen ,unspezifisch kranken", d. h. nicht schilddrüsenkranken Patienten [23] kommt es zu einer Vermehrung des dialysierbaren L-Thyroxin-131.Jods durch Verminderung der Bindungskapazität des Präalbumins. Erhöhte Aufnahmen von $\mathrm{T}_{3}-131$ durch Erythrocyten fanden Harocsky eta1. [11] bei Nephrosen, gewissen Lebererkrankungen, metastasierenden Carcinomen, erhöhtem $\mathrm{CO}_{2^{-}}$Partialdruck infolge respirato- 
rischer Insuffizienz, paroxysmaler Vorhofarrhythmie und Anticoagulantientherapie. Die Methode der Dextran-Gel-Filtration wurde von uns noch nicht systematisch daraufhin untersucht, bei welchen nicht thyreogenen Krankheitszuständen pathologische $T_{3}$-131-Proteinbindungsverhältnisse vorliegen können. Es darf vermutet werden, daß die Verhältnisse äbnlich wie beim $\mathrm{T}_{3}$-131-Erythrocyten-Aufnahmetest liegen.

Für die Höhe des Anteils an sog. freiem L-Trijodthyronin-131 Jod ist im wesentlichen die L-ThyroxinKonzentration im Serum verantwortlich [25]. Da umgekehrt das Thyroxin im Serum der wesentliche, die Höhe des proteingebundenen Jods (PB'127) bestimmende Faktor ist, war zu erwarten, daß zwischen $\mathrm{PB}^{127} \mathrm{I}$ und Höhe des sog. freien $\mathrm{T}_{3}-131$ Beziehungen nachweisbar sind. Wie oben mitgeteilt, sind diese Werte, wenn auch z. T. schwach, korreliert.

Angaben über die Wertigkeit klinischer Symptome und anamnestischer Hinweise für die Diagnose der Hyperthyreose sind nur dann ernsthaft verwertbar wenn die klinische Diagnose durch vollständige und zuverlässige Laboratoriumsuntersuchungen gesichert und untermauert wird [24-29], was nicht bei allen Mitteilungen zu diesem Problem der Fall war. Die Angaben über die Treffsicherheit der klinischen Untersuchung decken sich dabei weitgehend $[26-28,30]$. Bemerkenswert ist, daß man zumeist nur Angaben bezüglich der Differentialdiagnose zwischen euthyreoten und hyperthyreoten Funktionszuständen findet. Die meisten Autoren geben dafür eine Treffsicherheit von $85 \%$ an. Schwierigkeiten bestehen aber besonders bei Fällen mit oligosymptomatischen Formen der Hyperthyreose und bei Patienten mit ausgeprägter vegetativer Symptomatik und ferner bei hypothyreoten Funktionszuständen [31].

Die Diagnose der Hypothyreose ist in weniger ausgeprägten Fällen nicht nur klinisch, sondern auch blutchemisch oft sehr schwierig zu stellen. Fließende Übergänge zwischen euthyreotem und hypothyreotem Funktionszustand sind nicht selten, z. B. nach Thyreoiditis, Strumaresektion oder ${ }^{131}$ Jodtherapie [32, 33]. Bei der Hypothyreose überlappen die Werte für proteingebundenes. Jod. $\left(\mathrm{PB}^{127} \mathrm{~T}\right)$ und für den sog. freien und den proteingebundenen Anteil an $\mathrm{T}_{3}-131$ mit den Werten der Euthyreosen (s. o.). Nur bei der Untersuchung von ausgewählten, extrem pathologischen Sohilddrüsenunterfunktionen liegen die Werte für sog. freies und proteingebundenes $T_{3}-131$ ohne Überlappungen außerhalb der Normalbereiche $[6,34]$. Variation der Dextran-Gel-Menge bei der Gel-Filtration und die Durchführung von Verdrängungsversuchen ermöglichen, wie oben beschrieben, zusammen mit dem ${ }^{131}$ Jodspeicherungstest und der Bestimmung des proteingebundenen Jods in den meisten Fällen jedoch die Diagnose.

Mit den Hyperthyreosen wurden nur solche ,toxischen Adenome" verglichen (s. Ergebnisse), bei denen eine echte Schilddrüsenüberfunktion nachgewiesen wurde [35]. Definitionsgemäß ist das toxische Adenom ein gutartiger Schilddrüsentumor mit einer von der hypophysären Regulation unabhängigen Hormonbildung. Solche autonomen Zonen müssen nicht immer zu einer Überhöhung des Hormonspiegels im Blut führen, d. h. zu einer Thyreotoxikose, wie nach der etwas irreführenden Bezeichnung ,toxisches Adenom“" angenommen werden könnte. Ein mit der Szintigraphie erfaBbarer, vermehrt speichernder Bezirk in der Schilddrüse kann nämlich bei der Untersuchung des $\mathrm{PB}^{127} \mathrm{~T}$ und $\operatorname{der} \mathrm{T}_{3}$-131-Bindungsverhältnisse mit völlig normalen Werten einhergehen. Bei einem Teil dieser Fälle besteht also lediglich ein szintigraphisch warmer oder heißer Knoten [36]. Die Diagnose ,kompensiertes oder dekompensiertes toxisches Adenom" sollte als rein szintigraphisch deskriptiver Begriff verstanden werden. Klinisch müBte dann zwischen nichttoxischen, subtoxischen und toxischen Adenomen unterschieden werden [37]. Die Symptomatik der toxischen Adenome ist in vielen. Fällen durch ein frühzeitiges Auftreten kardialer Störungen (Extrasystolie, Tachyarrhythmie usw.) charakterisiert [35]. Hier besteht die Gefahr, durch den zur Diagnose eines kompensierten toxischen Adenoms notwendigen L-Trijodthyronin-Suppressionstest einen Angina pectoris-Anfall oder sogar einen Myokardinfarkt auszulösen, besonders bei hoher L-Trijodthyronin-Dosierung [16].

Bei der Auswertung der Radiojodspeicherungsteste fanden wir eine Anzahl von Patienten, die eine erhöhte 131. Jodidraffung (Jodidphase) und einen beschleunigten 131. Jodumsatz (Hormonjodphase) [38] zeigten, auch ohne daß eine Überfunktion vorlag. Dabei handelte es sich um ehemalige Hyperthyreosen, endokrine Ophthalmopathien ohne Überfunktion, operativ oder mit ${ }^{131}$ Jod verkleinerte Schilddrüsen und sogar um einfache Euthyreosen, die allerdings meistens mit einer Struma einhergingen [24, 29, 39]. - Eine gesteigerte Jodraffung ohne beschleunigten ${ }^{131}$ Jodumsatz findet man z. B. während der Schwangerschaft und bei Oestrogenmedikation, bei manchen kompensierten und dekompensierten Jodfehlverwertungen, beim sog. Hyperthyreoid [50] — wir nannten diese Fälle jodavide Euthyreosen - und bei Jodmangel [40-43]. Beim sporadischen euthyreoten Kropf finden sich oft niedrige Konzentrationen an anorganischem Jod im Plasma und erhöhte ${ }^{131}$ Jodumsätze [41]. Erniedrigte Werte des anorganisehen Jodids können mit erhöhter Schilddrüsenclearance für ${ }^{131}$ Jodid und erhöhter ${ }^{131}$ Jodaufnahme einhergehen [40]. Nach HaRRIson [42] haben Patienten mit einem Kropf nach der Diätanamnese eine erniedrigte Jodzufuhr - Abneigung gegen Fisch und dementsprechend eine herabgesetzte Jodausscheidung im Urin. - Ob der Jodmangel allein die Ursache des endemischen Kropfes ist, muB dahingestellt bleiben. Man diskutiert heute die Möglichkeit, daß ein Jodmangel auf einen latenten Defekt der Schilddrüsenhormonsynthese (abortive Dyshormonogenese) trifft und dann zum Entstehen eines Kropfes führt. DaB beim sporadischen Kropf nahezu regelmäBig ein Defekt der Hormonsynthese vorkommt, wurde von DrmITRIADOU berichtet [44]. Auch REINWEIN und KIEIN $[45,46]$ fanden den Gesamtjodgehalt der jodaviden Strumen gegenüber Strumen mit nur mäBig beschleunigtem Jodumsatz erniedrigt und nahmen für die letzteren Defekte der Hormonsynthese an. Von VIGIER [16] fand in einem Jodmangelgebiet (Bern), daß $40 \%$ (!) aller Euthyreosen eine erhöhte Umwandlungsrate für ${ }^{131}$ Jod aufwiesen und $20 \%$ ein erhöhtes PB ${ }^{131} I$. Wir können danach schließen, daß bei der Schilddrüsenüberfunktion zwar praktisch immer ein vermehrter ${ }^{131}$ Jodumsatz nachweisbar ist. Umgekehrt beweist dieser Befund allein jedoch keineswegs das Vorliegen einer Hyperthyreose. 
Ein besonderes Problem in der Schilddrüsendiagnostik bieten jene Fälle, deren ${ }^{131}$ Joddiagnostik durch extrathyreoidale Krankheitsprozesse und exogene Faktoren gestört wird. Diese Störfaktoren greifen an den verschiedensten Stellen der Hormonsynthese und deren zentraler Regulation, am Transport der Hormone im Blut oder am peripheren Wirkungsort $[26,29,39,43,47,48]$. Neuere Untersuchungsmethoden gestatten jedoch in den meisten Fällen eine Klärung des Schilddrüsenfunktionszustandes dadurch, daß auch sie an verschiedenen Stellen des Jodhormonstoffwechsels angreifen und eine Reihe von Parametern liefern, die mosaikartig zusammengetragen, Aussagen über die Schilddrüsenfunktion erlauben, auch dann, wenn die eine oder andere Untersuchung durch endogene oder exogene Faktoren unbrauchbar wurde.

Die Autoren danken der Deutschen Forsehungsgemeinschaft für eine Sachbeihilfe ( $\operatorname{Se~} 4 / 1+3$ ).

Frau D. SembenT und Frau E. Sambauer danken wir für ausgezeichnete technische Assistenz. Allen. Kollegen des Rieder-Institutes und der II. Medizinisohen Klinik, die an der klinischen Betreuung der Patienten beteiligt waren, insbesondere den Herren Dr. Bundn, Dr. Sonnract, Dr. Hör, Dr. Stimcrnofre und Dr. HAUBOLD, danken wir für ihre Hilfe. Für die Ausführung der Zeichnungen und Fotoarbeiten sind wix Herrn BESTLER und Fräulein HAAG zu Dank verpflichtet.

Zusammenfassung. Neben den bewährten älteren Verfahren zur Bestimmung des proteingebundenen ${ }^{127}$ Jods und des Radiojodumsatzes hat sich die gleichzeitige Bestimmung des sog. freien und des proteingebundenen Anteils an in vitro mit Serum inkubiertem L-Trijodthyronin-131Jod mittels Dextran-Gel-Filtration klinisch zur Differentialdiagnose von Hyperthyreose und Euthyreose bewährt. Bei Ausnützung der Verdrängung von proteingebundenem L-Trijodthyronin-131Jod durch nichtmarkiertes Hormon und bei Variation der Dextran-Gel-Menge in der Säule bietet die Methode gute Differenzierungsmöglichkeiten auch für die Schilddrüsenfunktionszustände Euthyreose und Hypothyreose. Bei dem Verfahren wird der Patient nicht mit radioaktivem Jod belastet, ein für die Kinderklinik wichtiger Gesichtspunkt. Manche Störfaktoren, die den ${ }^{131}$ Jodspeicherungstest und die $\mathrm{Be}$ stimmung des proteingebundenen Jods ( $\left.\mathrm{PB}^{127} \mathrm{I}\right)$ ver fälschen, haben keinen Einfluß auf die mit der Dextran-Gel-Filtration untersuchten Proteinbindungsverhältnisse für L-Trijodthyronin- ${ }^{131}$ Jod. So hat sich das Verfahren für die Untersuchung von Patienten mit operativ oder durch ${ }^{131}$ Jodbehandlung verkleinerten Schilddrüsen, mit endokrinem Exophthalmus und in Fällen mit vorausgegangener Jodgabe, z. B. in Form von Kontrastmitteln, besonders bewährt. Mit der Bestimmung des sog. freien L-Trijodthyronin-131 Jods wird ein physiologisch und pathogenetisch wichtiger Parameter der Schilddrüsenfunktion exmittelt. Die klinische Bedeutung der Bestimmung der Bindungsund Transportverhältnisse für Trijodthyronin mittels Dextran-Gel-Filtration wird diskutiert.

Summary. In addition to conventional methods of assay of protein bound iodine (PB $\left.{ }^{127} \mathrm{~T}\right)$ and of ${ }^{131}$ iodine turnover in the thyroid, the simultaneous determination of socalled free and protein bound 1-triiodothyronine-131I, added in vitro to serum, using dextran gel filtration was found to be clinically helpful for diagnosis of eathyroidism and hyperthyroidism. Fmploying discharge effects of non-labelled triodothyronine on protein bound 1-txiodothyronine-131I and varying the amount of dextran gel in the columns, the method provides reasonably good differentiation of euthyroid and hypothyroid states. No radioactive iodine is given to patients during this procedure, a fact of importance for pediatriciens. Some factors, that influence ${ }^{13}$ iodine uptake or PB $\mathrm{PB}^{127}$ levels, do not disturb protein binding of l-triiodothyronine-131 I as determined by dextran gel filtration. The latter method was found to be especially useful for the examination of patients with surgically, or by therapy with ${ }^{131}$ iodine dissected thyroid glands, with endocrine exophthalmos, and in cases of previous iodine administration (e.g. $X$-ray procedures). Determination of socalled free I-triiodothyronine-131I provides information about a factor of physiological and pathogenetical significance, its clinical meaning is discussed.

Literatur. [I] HamoLsmy, M. W., M. StBer, and A. S. FrewedBrag: The thyroid hormone plasma protein complex in man. A new in vitro method for study of "uptake" of labelled hormonal compounds by human erythrocytes. J. elin. Endocr. 17, 33 (1957). - [2] SHAPrRo, B., and J. I. Rabrvowrrz: A chromatographie method utilizing Sephadex for the separation of free iodide, protein-bound and unbound triiodothyronine in sera. A) Clinical correlations with the Hamolsky T-3-RBC-uptake method (108 eases). J. nuclear Med. 3, 417 (1962). - [3] RABNNOWITZ, J. L., B. SHAPrRo, and P. JoHNSON: "Sephadex chromatographio" test in the evaluation of thyroid function. J. nucl. Med.4, 139 (1963). - [4] STUMPF, W., u. F. H. GRAUL: In-vitro-Bestimmung der Schilddrüsenfunktion mit dem Serum-T $T_{3}$-Test. Med. Klin. 58 192 (1963). [5] Sortea, P. C., H. G. Heinze, R. Landgraf, K. W. Frey u. K. SCHWARZ: Untersuchungen über die Schilddrüsenfunktion mit Bestimmung der Verhältnisse von sog. freien zu proteingebundenem Trijodthyronin im Serum mittels Dextrangelfiltration. Verh. dtsch. Ges. inn. Med. 71 (1965) (im Druck). [6] CUarón, A., n. M. E. Fucugaverr: The binding of ${ }^{131}$ I-triiodothyronine by serum-proteins as an in vitro test of thyroid fanction. Acta endocr. (Kbh.) 46, 161 (1964). - [7] HorsTer, F. A., u. E. KLtars: Die Anwendung von radioaktivem Trijodthyronin zur Diagnostik der Schilddrüsenfunktion in vitro. Dtsch. med. Wschr. 89, 983 (1964). - [8] GodD सN, D. J., and E. S. GARNETT: The 131-triiodothyroninemresin-uptake test. J. Endocr. 29, 167 (1964). - [9] STERLING, K., and M. TABACHNICK: Resin uptake of $\mathrm{I}^{131}$-triiodothyronine as a test of thyroid. function. J. clin. Endocr. 21, 456 (1961). - [10] MITCHELL, M. L., A. B. HARDen, and M. E. O'Rourke: The in-vitroresin sponge uptake of triiodothyronine- $\mathrm{I}^{131}$ from serum in thyroid disease and in pregnancy. J. clin. Endocr. 20, 1474 (1960). - [11] HalrorsKY, M. W., A. Goldetz, and A. S. FreEDBERG: The plasma proteinthyroid hormone komplex in man. III. Further studies on the use of the in vitro red blood. cell

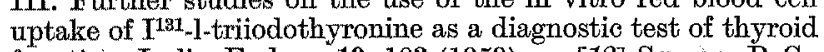
function. J. olin. Endocr. 19, 103 (1959). - [12] SCRIBA, P. C., R. LaNDGRaf, H. G. Heinze u. K. Schwarz: Bestimmung der Bindung von Trijodthyronin an Serumproteine mittels Dextran.Gel-Filtration. Klin. Wschr. 44, 69 (1966). - [13] BARKER, S. B., M. J. HUMPHREY, and M. H. SOLEY: The clinical determination of protein bound iodine. J. clin. Invest. 30, 55 (1961). - [14] ScrwrEGK, H., u. F. TuRBA: Künstliche radioaktive Isotope in Physiologie, Diagnostik und Therapie, 2. Aufl. Berlin-Göttingen-Heidelberg: Springer 1961. [15] LANDGRAF, $\mathrm{R}_{\text {. }}$ : Schilddrüsenfunktionsdiagnostik unter be-
sonderer Berückssichtigung der Bestimmung der Bindung von L-Trijodthyronin an Serumproteine mittels Dextran-GelFiltration. Diss. Universität München, 1966. - [16] VIGIER, v.: Probleme der Hyperthyreosediagnostik. Helv. med. Acta 31, 191 (1964). - [17] TAGUOHr, J. T., C. P. PowkiL, and N. F. NTCRkRson: Thyroidal I'131-uptake pattern following iodides. Arch. intern. Med. 112, 569(1963). - [18] SThRLING, K.: Thyroxine in blood. Proc. Mayo Clin. 89, 586 (1964). -

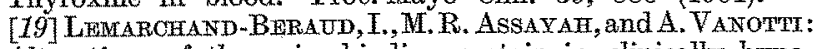
Alterations of thyroxine-binding protein in clinically hypoand hyperthyroid patients with normal PBI-Level. Acta endocr. (Kbh.) 45, 99 (1964). - [20] BravermanN, L. E., and S. H. INGBAR: Anomalous effects of certain preparations of dessicated thyroid on serum protein-bound iodine. New Engl. J. Med. 270, 439 (1964). - [21] DowLING, J. T., N. FreINkEL, and S. H. INeBAR:Thyroxine-binding by sera of pregnant women, newborn infants and women with spontaneous abortion. J. clin. Invest. 35, 1263 (1956) - - [22] SuRKs, M. I., and J. H. OpPenmermar: Postoperative changes in the concentration of thyroxine-binding prealbumin and serum free thyroxine. J. olin. Endocr. 24, 794 (1964). - [23] OPPENHEMMER, J.H., R. SQukF, M. I. SURKs, and H. HaUER: Binding of thyroxine by serum proteins evaluated by equilibrium dialysis and elektrophoretic techniques. Alteration in 
non-thyroidal illness. J. clin. Invest. 42, 1769 (1963). [24] Horst, W., I. Peternsen, J. K. Thummann u. L. ZuUKschwERDT: Methoden und Ergebnisse der Differentialdiagnostik von Schilddrüsenerkrankungen durch die Szintigraphie und das Radiojod-Dreiphasenstudium. Dtsch. med. Wsohr. 85, 711 (1960). - [25] SANTOS, M. A., and J. L. RABINowIT: L-triiodothyronine binding to Serum protein. Competition by thyronine. Proc. Soc. exp. Biol. (N.Y.) 115, 901 (1964). - [26] Krmis, E.: In: Fortschritte der Sohilddrüsenforschung (Hrsg. K. OBERDISSE u. E. KLETN), S. 81. Stuttgart: Georg Thieme 1962. - [27] GüNTHER, R., G. LaUbrname, G. Gentmis, W. Skjilhetm, C. Damman u. A. KerR: Über die Aussagefähigkeit der klinischen Untersuchung zur Beurteilung der Sohilddrüsenfunktion. Med. Klin. 59, 930 (1964) [28] Börner, W., M. LaUtsch u. E. Molt: Diagnostik der Schilddrüsenerkrankungen. Med. Welt 18 (1965). [29] KLEIN, E.: Schilddrüsenfunktion und Jodstoffwechsel (Grundzüge der Schilddrüsendiagnostik). Internist (Berl.) 4, 297 (1963). - [30] Gold, A., B. P. MurPhy, and C. J. PATTTE: Evaluation of the diagnostic validity of a new method of serum thyroxin assay. Proceed. Vth Internat. Thyroid Conference, Rome, 1965, Abstr. 224. - [31] KLUWE, H., u. D. FAR scrIDPUR: Fehldiagnosen der Hypothyreose. Dtsch. med. Wschr. 88, 2456 (1963). - [32] DuNN, J. T., and E. ChapMraN: Rising incidence of hypothyroidism after radioactive-iodine therapy in thyrotoxicosis. New Engl. J. Med. 271, 1037 (1964). - [33] GreEN, M., and G. M. WILSON: Thyrotoxicosis treated by surgery or iodine-131. Brit. med. J. 1964I, 1005. [34] CUarón, A.: The in vitro uptake of ${ }^{131}$ I-triiodothyronine by erythrozytes and its binding by serum proteins. Proc. Vth Internat. Thyroid Conference, Rome, 1965 Abstr. 67. [35] GoLd, E.: Das toxische Adenom der Schilddrüse (Plummers disease). Wien. klin. Wschr. 76, 404 (1964). - [36] UrHeENANNT, H., u. J. WeINREICH: Über das toxische Adenom der Schilddrüse. Med. Klin. 60, 704 (1965). - [37] VAGUE, J. R. Stwontr, G. Mrulder, and A. AlLAND: Diagnosis and evolution of autonomous thyroid nodules. Proceed. Vth Internat. Thyroid Conference, Rome 1965, Abstr. 58. [38] Horst, W.: Methoden und Ergebnisse des Radiojodstoff- wechselstudiums zur Diagnostiik thyroidaler und extra thyreoidaler Erkrankungen. Radiojodzweiphasenstudium. Klin. Wschr. 30, 439 (1952), - [39] VANOTTr, A.: Beeinflussung der Radiojoddiagnostik durch extrathyroidale Krankheitsprozesse und exogene Faktoren. Verh. dtsch. Ges. inn. Med. 70,851 (1964).- - [40] WAYNY, E. J., D. A. KouTras, and W. D. ALEXANDER: Clinical aspects of iodine metabolism, p. 237 . Oxford: Blackwell Sci. Publ. 1964. - [41] ABovL-Kratr, S.A. and J. Crooks: A comparative study of iodine metabolism in pregnancy, sporadic goitre and thyrotoxicosis. Acta endocr. (Kbh.) 48, 14 (1965). - [42] Harrison, M. T., R. MCG. HaRDEN, and E. WAYNE: Iodine balance studies and the availability of iodine. Proc. Vth Internat. Thyroid Conference Rome 1965, Abstr. 101. - [43] HoRst, W.: Klinische Radiojoddiagnostilk der Schilddrüsenerkrankungen. In: Strahlenbiologie, Strahlentherapie, Nuclearmedizin und Krebsforschung, S.789. Stuttgart: Georg Thieme 1959. - [44] DimIrriadođ, A., R. SUWANTK, and R. Fraser: Chromatographic studies on biopsy specimens from nontoxic goitres in London compared with those in Thailand. Proc. roy. Soc. Med. 57, 361 (1964). [45] RuINwetN, D., 1. E. KuatN: Die Zusammensetzung der jodhaltigen Verbindungen und ihre Beziehung zum Jodumsatz in euthyreoten Strumen. Acta endocr. (Kbh.) 41, 584 (1962). [46] REtrwan, D.: Über die Pathogenese der Struma. Dtsch. med. Wschr. 88, 2493 (1963). - [47] Marinis, S., S. Debiasi u. E. KALLEE: Verdrängung von ${ }^{13} \mathrm{~J} J$-Trijodthyronin durch anionische Medikamente im Trijodthyronintest. Acta isotopica 3, 269 (1963). - [48] Havsen, H. H., and E. F. MogENSEN: The effect of sodium salicylate on the uptake of 131I labelled L-triiodothyronine by human erythrocytes. Acta med. scand. 175, 687 (1964). - [49] DImM, K.: Documenta Geigy, wissenschaftliche Tabellen, J. R. Geigy, S. A., Basel 1960 , S. 146ff. - [50] Heinntwa, K.: Das Hyperthyreoid. Dresden u. Leipzig: Theodor Steinkopff 1962.

Dr. med. Peter C. Soriba

Priv. Doz. Dr. med. K. Sonwarz

II. Med. Klinik der Universität München 8 München 15, Ziemssenstr. 1

\title{
Die Auswirkung einer portocavalen Anastomose bei Lebercirrhose auf freie Plasmaaminosäuren und Blutammoniak nach oraler Proteinzufuhr
}

\author{
H. G. Knauff, H. Hamelimann, D. Seybold und A. Kanters \\ Medizinische Klinik der Universität Marburg (Dir.: Prof. Dr. G. A. MartinI), II. Medizinische Klinik \\ (Dir.: Prof. Dr. Dr. G. BoDechtes) und Chirurgische Klinik (Dir.: Prof. Dr. R. ZENkER) der Universität München
}

Bei schweren Lebercirrhosen ist in der Regel der Plasmaspiegel einiger freier Aminosäuren deutlich verändert $[5,6,15-18,25,36]$. Wir fanden ziemlich konstant eine Vermehrung von Tyrosin, Phenylalanin, Methionin, Prolin und Alanin, in einigen Fällen auch von Leucin [17]. Diese Veränderungen gingen dem Schweregrad des Krankheitsbildes etwa parallel, waren aber auch bei schweren Fällen oft noch recht diskret. Deutlichere Veränderungen wurden sichtbar, wenn wir die Patienten mit einer Proteinmahlzeit belasteten [16]. Offenbar kann der Spiegel der meisten Aminosäuren unter Ruhe bedingungen noch konstant gehalten werden. Die funktionelle Reserve der geschädigten Leber reicht aber nicht aus, um größeren Mehranforderungen gerecht zu werden.

Das im Stoffwechsel entstehende Ammoniak wird vornehmlich in der Leber zu Harnstoff entgiftet $[7,20$, 24, 28, 34]. Bei schweren Cirrhosen ist diese Funktion beeinträchtigt, das Blutammoniak daher meist deutlich erhöht $[13,16,18,27,31,33,35]$. Eine reichliche Proteinmahlzeit bedeutet dann eine zusätzliche Belastung, da das durch die Darmbakterien und den Aminosäureabbau im Organismus vermehrt gebildete Ammoniak nur langsam in Harnstoff überführt werden kann. Der Ammoniakspiegel steigt weiter an und kann toxische Konzentrationen erreichen.
Nach Anlegung einer portocavalen Anastomose gelangen freie Aminosäuren und Ammoniak unter Umgehung der Leber direkt aus dem Darm in den großen Kreislauf [30,31]. Dadurch ist der Ammoniakspiegel im Blut bei solchen Fällen stärker erhöht, als es dem Grad der Leberschädigung entspricht. Dies ist durch zahlreiche klinische und experimentelle Untersuchungen gut gesichert $[4,9,21,22,33]$. Wie sich eine solche Anastomose auf die freien Plasmaaminosäuren auswirkt, wurde dagegen bisher noch nicht untersucht. Auch ist nicht bekannt, wie lange der Organismus benötigt, bis die Konzentration der einzelnen Aminosäuren nach einer Proteinmahlzeit zur Norm zurückkehrt.

Da wir kürzlich über den EinfluB einer oralen Proteinbelaștung auf Plasmaaminosäuren und Blutammoniak von Kranken mit Lebercirrhose berichteten [16], lag es nahe, diese Untersuchungen bei Patienten mit gleichschwerer Cirrhose und operativ angelegter portocavaler Anastomose zu wiederholen.

\section{Methodik}

Unser methodisches Vorgehen entsprach in allen Einzelheiten dem unserer früheren Versuchsserien. Wir entnahmen von sämtlichen Versuchspersonen morgens nüchtern $40-50 \mathrm{ml}$ Cubitalvenenblut. Danach bekamen sie $1 \mathrm{~g}$ Protein $/ \mathrm{kg}$ Körpergewicht in Form eines in Wasser suspendierten Milchpulver- 